\title{
LENGUAS EN PELIGRO EN COSTA RICA: VITALIDAD, DOCUMENTACIÓN Y DESCRIPCIÓN ${ }^{1}$
}

\author{
Carlos Sánchez Avendaño*
}

\begin{abstract}
RESUMEN
En este artículo se examinan los datos relativos a la vitalidad sociolingüística y estructural de las lenguas en peligro en Costa Rica, de acuerdo con las caracterizaciones panorámicas y específicas para cada lengua publicadas hasta la fecha y según el modelo propuesto por la UNESCO. Además, se comenta sobre el estado de la documentación y descripción de cada uno de los idiomas minoritarios del país.

Palabras clave: lenguas en peligro en Costa Rica, vitalidad sociolingüística, vitalidad estructural, documentación lingüística, descripción lingüística.
\end{abstract}

\begin{abstract}
In this article, data related to the sociolinguistic and structural vitality of the endangered languages in Costa Rica are examined, according to both the panoramic characterizations and the characterizations for each language that have been published so far and also in tune with the UNESCO model. Besides, the state of the documentation and description of each minority language in the country is commented on.

Key Words: endangered languages in Costa Rica, sociolinguistic vitality, structural vitality, linguistic documentation, linguistic description.
\end{abstract}

\section{Introducción}

En la actualidad, según se desprende de lo reportado en diversos estudios cualitativos y cuantitativos (Margery 1993c, Quesada Pacheco 2008a, Sánchez Avendaño 2009a), se puede afirmar que cuatro de las lenguas habladas históricamente en el territorio costarricense están atravesando por un proceso de desplazamiento: el malecu (maleku, guatuso), el bribri, el cabécar y el inglés criollo limonense (Limon English, creole, mekaytelyw, mecateliu, Limon tak). Si bien se trata de la lengua amerindia con mayor vitalidad en Costa Rica y con el mayor número de hablantes en Panamá, todo apunta a que el nove (ngäbe, guaymí, move, movere, ngöbe, ngäbere) también está experimentando un proceso de sustitución en Costa Rica (Sánchez Avendaño 2009a). Asimismo, el buglere (bocotá, guaymí sabanero, sabanero, buglé) es catalogado como en serio peligro de extinción por Quesada (2008a) en lo que respecta a los asentamientos costarricenses.

Todas estas lenguas -algunas de las cuales solo se hablan en Costa Rica (tal es el caso del malecu y el cabécar)- parecen estar encaminándose al mismo estado de obsolescencia que caracteriza al boruca (brunca, 
brún̈cajc, brúnkajk) y al térraba, los dos idiomas indocostarricenses que en época reciente han alcanzado los grados máximos de declinación (Quesada Pacheco 2008a, Sánchez Avendaño 2009a). En este panorama, también habría que considerar el precario estado de la variedad "más autóctona" de la lengua de señas costarricense (LESCO), la cual desde hace varias décadas ha venido siendo reemplazada de forma progresiva por una nueva variedad con fuerte influjo de la lengua de señas estadounidense, de modo que aparentemente solo es hablada en el presente por algunas personas mayores. Hasta la fecha, esta variedad de LESCO no ha sido ni descrita ni documentada (Woodward 1991, 1992; Retana 1993).

En el presente artículo, examinaremos los datos relativos a la vitalidad sociolingüística y lingüística (estructural) de las lenguas de Costa Rica en peligro y nos referiremos al estado de su documentación y descripción. El mapa 1 muestra la ubicación territorial y recoge algunos de los glotónimos de las lenguas de las que se ocupa este artículo, con excepción de las variedades de LESCO, cuyos usuarios no conforman una comunidad etnolingüística con territorio definido.

MAPA 1

LENGUAS EN PELIGRO EN COSTA RICA

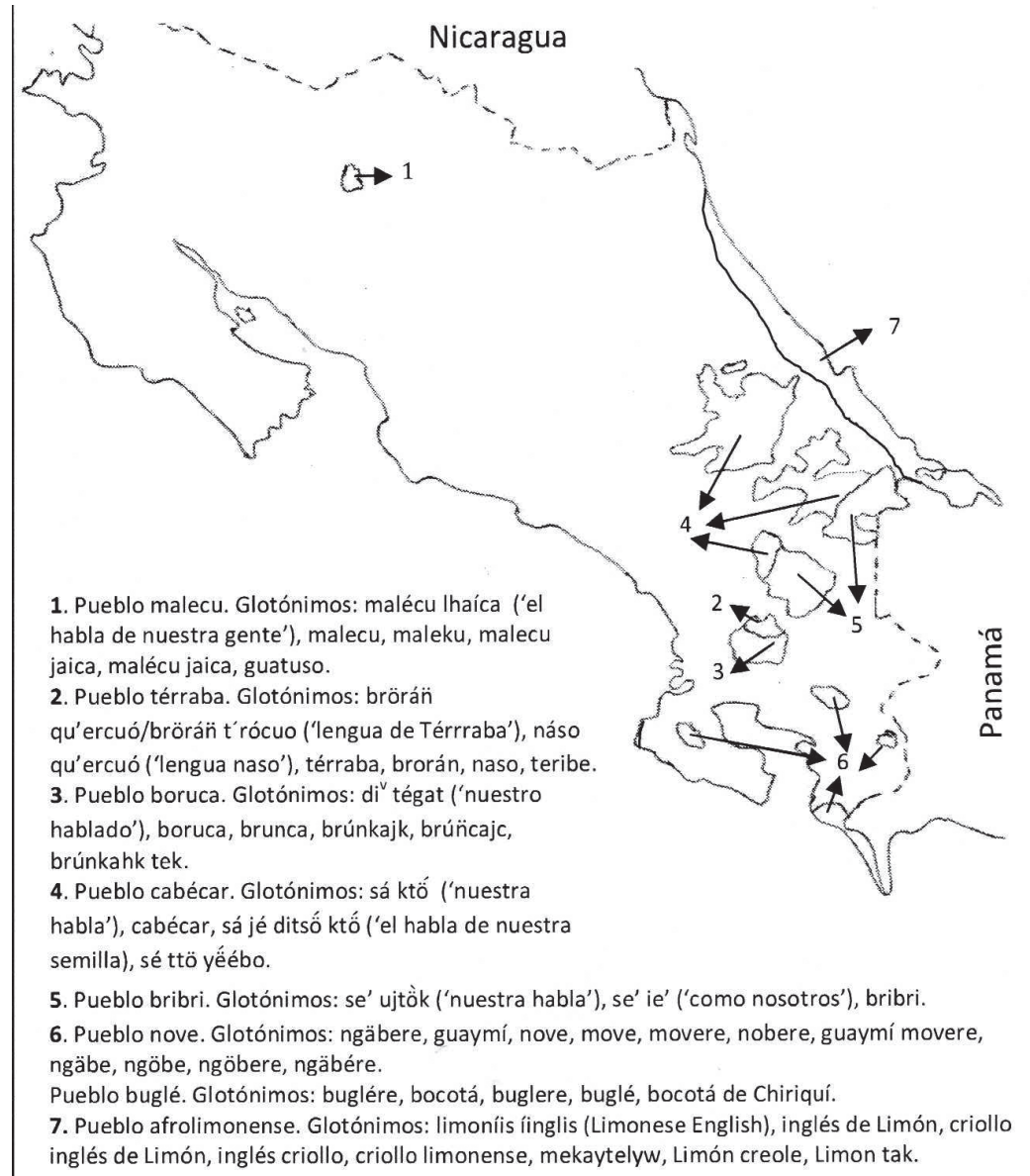




\section{La vitalidad de las lenguas de Costa Rica en peligro: Estado de la cuestión}

La caracterización de la situación sociolingüística actual de Costa Rica en lo relativo al estado de conservación de las lenguas minoritarias y su proceso de desplazamiento se halla esbozada de forma panorámica en Margery (1993c), Quesada Pacheco (2008a) y Sánchez Avendaño (2009a). En estos estudios se concluye que todos los idiomas indocostarricenses y el inglés de Limón están amenazados, pues sus esferas de uso continúan reduciéndose y su transmisión intergeneracional ha cesado por completo o muestra signos de haber disminuido drásticamente.

Los autores que se han ocupado de la determinación de la vitalidad de estas lenguas han recurrido básicamente a dos modelos: el modelo de la vitalidad etnolingüística de Giles et al (1977) $)^{2}$, en el caso de Herzfeld (2011), y el modelo de Bauman $(1980)^{3}$, en el caso de Margery (1993c), Quesada Pacheco (2008a, 2008c), Quesada (2008a), Murillo (2008) y Castro (2008). Por su parte, Sánchez Avendaño (2009a) lleva a cabo un análisis basado en el cálculo de la pérdida de hablantes de acuerdo con información estadística contrastada con observaciones etnográficas. Finalmente, algunos autores se han decantado por centrarse en las esferas de uso y las actitudes lingüísticas en el estudio de la declinación de lenguas específicas (Portilla 1986; Constenla 1988; Umaña 1991; Spence 1997, 2001), mientras que Quesada (2008b) propone una tipología basada en los parámetros de preservación y defensa de los idiomas.

A continuación se reseña la caracterización de la vitalidad de las lenguas minoritarias costarricenses según los estudios que se han publicado al respecto. Los dos apartados en los que se organiza la información responden a los dos grandes intereses de investigación relacionados con los procesos de muerte de lenguas (Fasold 1996): la vitalidad sociolingüística (cantidad de hablantes, dominios funcionales, actitudes lingüísticas) y la vitalidad lingüística o estructural (obsolescencia, atrofia lingüística, cambios en los sistemas fonológicos y morfosintácticos patrimoniales, invasión léxica).

\subsection{Vitalidad sociolingüística}

El modelo de la vitalidad etnolingüística de Giles et al (1977) le sirve de base a Herzfeld (2011) para plantear una caracterización cualitativa de la situación del inglés limonense. El escaso control de la situación económicofinanciera de la provincia de Limón por parte de los afrodescendientes y las reducidas oportunidades laborales de estos hacen pensar a Herzfeld que el estatus económico de la comunidad es bajo. Por su parte, el estatus social parece ser mejor, debido a que se ha producido un resurgimiento del orgullo étnicolingüístico en época reciente, manifestado en el aprecio por la música y los juegos tradicionales, así como por el empleo del inglés criollo en diversas actividades. Asimismo, esta lingüista considera que el estatus de la lengua se ha visto beneficiado por la producción literaria de reconocidos escritores, pese a que el idioma no ha pasado por un proceso de estandarización.

Debido al mantenimiento de la mayoría de la población en el territorio ancestral y al constante vínculo de los emigrados con sus familias, Herzfeld infiere que la solidaridad grupal se conserva, lo cual ayuda a la vitalidad del criollo, si bien el aumento de la población hispanocostarricense y nicaragüense en la región pone en peligro la vitalidad del inglés limonense en lo que se refiere al factor demográfico. Finalmente, en cuanto al apoyo institucional, pese a que no existe una política oficial para el resguardo de esta lengua, Herzfeld considera que la expansión de la enseñanza del inglés en Costa Rica podría funcionar como aliciente para la conservación del criollo limonense. No obstante, esta autora supone que la alta frecuencia del cambio de códigos y del empleo de hispanismos revela una situación de desplazamiento gradual.

En lo que respecta a las lenguas indocostarricenses, con base en el modelo de Bauman (1980), Margery (1993c) expone que 
el nove se encuentra en estado de resistencia; el cabécar, el bribri, el malecu y el buglere están en estado de declinación; y el boruca y el térraba son lenguas en estado de obsolescencia. En opinión de este lingüista, los bribris, cabécares, malecus y bugleres se ubicaban, hasta hace poco tiempo, en regiones de difícil acceso o en áreas aisladas, pero en el presente la reducción de la cantidad de hablantes nativos y el avance del bilingüismo constituyen el resultado de la pérdida de tierras y la emigración desde los territorios originales. Estas cuatro lenguas se usan en tres esferas: la familiar, la ceremonial y la de la tradición oral.

De acuerdo con el informe de Margery, ya hace veinte años el boruca y el térraba carecían de hablantes monolingües y el número de hablantes semifluidos (que entendían la lengua) e infrafluidos (que recordaban algunas palabras) era muy pequeño. Además, estas dos lenguas no conservaban dominios de uso. Según este académico, el desplazamiento de ambos idiomas se debe a su localización en tierras de fácil acceso, especialmente para los campesinos hispanocostarricenses, y al proceso de aculturación promovido por el sistema educativo nacional.

Casi dos décadas después, Quesada Pacheco (2008a) también recurre al modelo de Bauman para caracterizar el estado de vitalidad de las lenguas del Área Intermedia de América, región dentro de la cual se hallan los idiomas de Costa Rica. Si bien este autor, al igual que Margery, continúa considerando el nove en estado de resistencia y el malecu, el cabécar, el bribri, el buglere y el inglés criollo en estado de declinación, cataloga el térraba y el boruca como idiomas extintos, estadio posterior al de la obsolescencia en la tipología de Bauman.

En el estudio panorámico publicado más recientemente, Sánchez Avendaño (2009a) examina, de forma comparativa, los datos acerca de las cifras de hablantes de las lenguas minoritarias de Costa Rica en los censos nacionales de población de 1927, 1950 y 2000. Asimismo, estudia con detalle los datos del 2000, debido a que estos arrojan información pormenorizada para cada región dentro de los territorios indígenas y consignan tanto el número de hablantes por herencia (individuos que declaran hablar el respectivo idioma vernáculo como lengua materna) como el de hablantes por competencia (usuarios actuales de las lenguas autóctonas). Finalmente, contrasta los datos estadísticos con la información etnográfica encontrada en diversas fuentes y somete a evaluación las cifras del censo del 2000 en relación con datos del Ministerio de Educación Pública de 1987 y 1997. A partir de los resultados obtenidos acerca de la transmisión intergeneracional y la proporción de hablantes con respecto a la población total de los diversos pueblos, Sánchez concluye que la pérdida de vitalidad de las lenguas amerindias es patente.

Aparte de los estudios reseñados y de breves referencias en diversas publicaciones, existen varios trabajos monográficos en los que se caracteriza el estado de conservación del boruca, el buglere, el térraba, el malecu, el nove y el inglés criollo limonense. En estos, o bien se evalúa la vitalidad o bien al menos se trata el tema con cierto detalle. Por ejemplo, a partir de su experiencia de trabajo de campo en La Casona (Limoncito, Coto Brus), Quesada (2008a) considera que el buglere en Costa Rica se encuentra en un estado intermedio entre la declinación y la obsolescencia.

En lo concerniente al nove, en Quesada Pacheco (2008c) y en Murillo (2008), esta lengua se cataloga como resistente o duradera, según la tipología de Bauman, sea porque se establezca una caracterización general de su situación sociolingüística tomando en cuenta a las comunidades de Panamá (como ocurre en Quesada Pacheco 2008c) o porque se determine que la situación particular en los asentamientos en Costa Rica es de alta vitalidad, de acuerdo con los parámetros de Bauman (como sucede en Murillo 2008).

En cuanto al térraba, de los datos de Portilla (1986) se concluye que el estado de esta lengua hace más de dos décadas era de clara obsolescencia, hecho que no solo se revelaba en el escasísimo número de hablantes fluidos y semifluidos (todos ellos ancianos), sino también en la práctica inexistencia de esferas de uso. 
En lo que respecta al boruca, Castro (2008) examina la situación de vitalidad de este idioma según cada uno de los parámetros de Bauman y concluye que este debe ser catalogado como una lengua extinta, mientras que Quesada Pacheco (2008c), también basándose en el mismo modelo de Bauman y analizando con detalle cada uno de los factores en el caso del boruca, considera que este idioma está en grave peligro de extinción.

Con base en los resultados de una encuesta diseñada para evaluar la situación sociolingüística de la lengua malecu, Constenla (1988) constata el evidente desplazamiento de este idioma y la preferencia por el empleo del español por parte de las personas de menor edad. En lo relativo a las actitudes hacia el malecu y el español, este lingüista encontró que los datos mostraban el predominio de una actitud positiva hacia la lengua autóctona, aunque parecía que la lealtad hacia ella empezaba a debilitarse en los más jóvenes, pese al orgullo étnico característico de los malecus. Sánchez Avendaño (2011) estudia el progreso de la pérdida de vitalidad de esta lengua a más de veinte años del diagnóstico de Constenla y halla que la situación se ha agravado, pues el desplazamiento se generalizó a todas las comunidades y la transmisión intergeneracional casi ha cesado por completo, si bien el malecu todavía conserva dominios de uso y las actitudes parecen ser predominantemente favorables.

En lo que respecta al inglés criollo limonense, Umaña (1991), tras analizar las respuestas de un cuestionario sociolingüístico, encuentra que, a menor edad de la persona, mayor inclinación y preferencia a aprender primero el español que el criollo, lo cual -a su parecer-, aunque no necesariamente se corresponde con la realidad comunicativa, sí indica el mayor prestigio del español. Además, esta autora comenta sobre la estigmatización histórica que ha sufrido el inglés criollo, considerado en muchos casos como un "inglés malo", y analiza casos de cambio de código que apuntan al desplazamiento del criollo en las nuevas generaciones.

Este mismo prejuicio sobre la calidad lingüística del criollo lo encontró Herzfeld (1994) en su trabajo de campo durante la década de
1970, si bien, en lo que respecta a los dominios de uso, también halló que el criollo compartía el espacio con el español en las interacciones familiares, con los vecinos y en los eventos religiosos, mientras que el español predominaba en los ámbitos laborales y para la lecto-escritura.

Empero, los datos recogidos dos décadas después por Spence (1997) muestran cómo ha disminuido la transmisión intergeneracional del inglés limonense a favor del español, incluso en la interacción entre los jóvenes y sus abuelos, y cómo en las generaciones más jóvenes predomina el empleo del español. Posteriormente, Spence (2001) encuentra correlación entre el estatus socioeconómico y educativo alto y la preferencia por el uso del español, en correspondencia con la escasa participación de las personas de este estrato social en reuniones ligadas a esferas de uso tradicionales del criollo. Por su parte, Winkler (2000) también señala que la transmisión intergeneracional del criollo limonense ha cesado en muchas familias y que se encuentran individuos menores de 18 años con escasa competencia en inglés o de plano ya solo con competencia pasiva en esta lengua.

Finalmente, Zimmer (2011) indica que el criollo limonense corre peligro de desaparecer por dos vías: por su descriollización hacia el inglés o por su sustitución por parte del español. En su estudio, esta lingüista también encuentra una disminución de la transmisión y del uso del criollo en los hogares, así como la aparición del bilingüismo pasivo y de la adquisición parcial o incompleta del criollo en las nuevas generaciones. Aun así, una gran mayoría de los jóvenes encuestados declararon tener una muy buena competencia en criollo y las actitudes hacia esta lengua fueron predominantemente favorables, sobre todo en lo que respecta a la lealtad lingüística, la conexión identitaria y el valor de la herencia cultural, así como en lo concerniente a la necesidad de conservar el idioma vernáculo, pese a que persiste su estigmatización y su consideración de "broken English". De este modo, de los resultados de todos los estudios reseñados se puede concluir que el inglés criollo limonense se encuentra en estado de declinación. 
En lo relativo a la lengua de señas costarricense (LESCO), se desconoce el número de personas sordas usuarias de este idioma, sea con un alto grado de competencia o con algún conocimiento mínimo de la lengua, sea como señantes nativos o como individuos que adquieren la lengua en una etapa "avanzada" de la vida ${ }^{4}$. A pesar de ser en estos momentos el idioma de Costa Rica menos estudiado, el LESCO es quizás la lengua minoritaria costarricense en menos peligro. Lejos de hallarse en declinación, podría estar experimentando más bien un proceso de florecimiento. Es posiblemente también la lengua minoritaria más estudiada por los hispanocostarricenses, la más visibilizada en los medios de comunicación masiva, y la que cuenta con más organizaciones preocupadas por controlar quién la enseña y cómo se enseña, así como por presionar a las instancias de poder para que se reconozca su estatus. Más adelante se comentará sobre la variación lectal del LESCO.

\subsection{Vitalidad estructural}

En cuanto al cambio estructural de las lenguas en proceso de desplazamiento en Costa Rica debido al contacto lingüístico, los fenómenos más sobresalientes consisten en la modificación de los sistemas fonológicos patrimoniales (incorporación de nuevas oposiciones desconocidas en el sistema más conservador) y en el préstamo léxico. Ambos aspectos están íntimamente relacionados, pues, en general, la entrada de hispanismos en el léxico es lo que produce la aparición de nuevos fonemas y nuevas oposiciones. Al respecto, Quesada Pacheco (2008a) sostiene que la interferencia del español en las lenguas vernáculas varía de acuerdo con el tema y la modalidad discursiva. Así, la narrativa tradicional suele presentar pocos hispanismos, mientras que los intercambios cotidianos muestran mayor influencia del español.

De acuerdo con Margery (1993c), en cabécar y en bribri, por ejemplo, se han incorporado los fonemas /f/ y /1/ por medio de los antropónimos, así como la curva entonativa ascendente como marcador de las preguntas; se encuentra también el empleo del marcador de plural en los sustantivos no humanos, la elisión del marcador de caso ergativo y la colocación de los demostrativos antepuestos al sustantivo ${ }^{5}$. En el caso del malecu, se aprecia la incorporación de cuatro fonemas en el sistema fonológico más innovador $(/ b /, / d / / g / \mathrm{y} / \mathrm{n} / 6)$, lo cual tiene incidencia incluso en la aparición de oposiciones que la lengua no conocía anteriormente, como se aprecia en los pares mínimos bóto "voto (electoral)' / póto 'indio voto', píña 'piña' / pina 'tiquisque' (Constenla 1998).

Para finales de la década de 1980, Constenla (1988) señalaba que, según su impresión, la influencia del español en la lengua malecu aún no era significativa y que, mediante el uso de préstamos o de creaciones léxicas con los mismos recursos del idioma, había escuchado a individuos malecus hablar de temas ajenos a su cultura tradicional. Diez años más tarde, este mismo lingüista (Constenla 1998) agrega que el contexto comunicativo y el tema de la conversación determinaban la mayor o menor presencia de hispanismos léxicos $\mathrm{y}$, por lo tanto, de innovaciones fonológicas en malecu.

De acuerdo con Quesada Pacheco (2008a), existen dos ámbitos léxicos, con estrecha relación con la cultura, en los que el influjo castellanizante ha calado más hondo, ya que incluso los elementos patrimoniales se han visto reemplazados en gran medida por las prácticas lingüísticas de los hispanohablantes: los sistemas numerales y la onomástica.

El otro tipo de elementos hispánicos que parece incorporarse con mayor frecuencia es el de los nexos discursivos y gramaticales, lo cual correspondería a la primera etapa de precarización estructural (anterior a la invasión léxica y a la erosión de los sistemas fonológicos y morfosintácticos) señalada por Hagège (2002) como parte del proceso de muerte de lenguas. Por ejemplo, en Constenla y Maroto (1979) se registran las preposiciones 'desde' y 'hasta' y las conjunciones 'o' y 'pero' en el discurso boruca. Para esta misma lengua, Quesada (2000a) indica que su informante llenaba las pausas con el relleno 'este'. En los textos bribris publicados por 
Jara y García (2008), se aprecia la incorporación de conectores como 'aunque', 'porque', 'pues', 'ahora', 'bueno', 'y', 'por eso' y -con mucha mayor frecuencia- 'pero'. Por último, Jara (2004b) encuentra que los hispanismos de tipo discursivo o nexual (v.g. 'ahora', 'entonces', 'porque', 'pero', 'es que') son más frecuentes que los nominales (v.g. 'piña', teléfono', 'guardia') en un texto conversacional bribri.

La interferencia más extrema del español en las lenguas indígenas costarricenses se halla en el discurso de los últimos hablantes del térraba y del boruca. Para el térraba, Portilla (1986) describe fenómenos de desfonologización de determinadas oposiciones, la reducción de reglas obligatorias, cambios del orden sintáctico tradicional, confusión en la asignación de los sustantivos a las distintas clases nominales (marcadas por diferentes clasificadores numerales) y reducción del caudal léxico. Por su parte, para el boruca, Quesada Pacheco (1995a, b) observa que el habla de las personas semifluidas revela la pérdida o inseguridad en el empleo de segmentos fonológicos (como el fonema laríngeo de este idioma) y en las oposiciones tonales, además del desplazamiento de formas verbales (como el pretérito pluscuamperfecto de esta lengua) y la pérdida de los significados más abstractos de los lexemas y de elementos que no se encuentran en español (como los adverbios de movimiento).

Para el boruca también se cuenta con una descripción de la competencia lingüística de un hablante "terminal". Quesada (2000a) explica que este, pese a haber adquirido el boruca como idioma materno, a hablarlo con cierta regularidad hasta la muerte de su esposa en 1984 y a haber sido capaz de narrar en boruca historias tradicionales, muestra signos claros de atrofia lingüística (tales como la mezcla de estructuras, significados y sonidos). Así, en el nivel fonológico, Quesada encontró la realización aproximante de /p, t, k/ en posición intervocálica. Empero, el componente morfosintáctico parecía intacto en el habla del hablante entrevistado, exceptuando lo que corresponde a algunos aspectos de categorías gramaticales regidas fundamentalmente por parámetros discursivos.
En cuanto al componente léxico, se aprecia confusión de pares opuestos y de miembros del mismo campo léxico, así como problemas para encontrar la palabra equivalente en boruca para la que se provee en español. También parecía afectada la capacidad del hablante para producir discurso conectado (por problemas con las reglas de referencia anafórica y con el sistema de foco relacionado con el estatus nuevo/dado de los referentes). Por lo demás, la producción del hablante se caracterizaba, según este lingüista, por la gran cantidad de hispanismos léxicos y de conectores discursivos, incluso de frases completas. Debido a esto, Quesada piensa que el componente textual podría ser uno de los primeros que se vea afectado en los casos de muerte de lenguas, aunque el hablante sea capaz de proporcionar oraciones aisladas bien construidas en términos sintácticos.

En lo que respecta al inglés limonense, Herzfeld (2002, 2011) encuentra que la alternancia de este idioma con el español y la presencia de hispanismos y de interferencias morfológicas en el discurso en criollo son frecuentes. Por su parte, Winkler (2000) apunta que, actualmente, la modalidad discursiva monolingüe en inglés o en criollo es rara en Limón, pues casi siempre se introducen préstamos del español. Para esta autora, si se interrumpe la transmisión del inglés y del criollo, se producirá un reemplazo completo del criollo, al sustituirse la matriz gramatical inglesa por la española. Zimmer (2011) también destaca la incorporación de préstamos léxicos del español y, en menor medida, de estructuras gramaticales. Así, se puede apreciar cómo, desde el estudio de Umaña (1991), se viene interpretando el incremento de la invasión léxica del español en el criollo de Limón y la frecuente mezcla de códigos como indicadores del probable reemplazo de la lengua vernácula.

No obstante la presunta buena vitalidad sociolingüística del LESCO, es necesario tomar en cuenta que existen dos variedades de este idioma y que la más empleada en la actualidad es producto de un proceso de relexificación acaecido en la década de 1970. De acuerdo con Retana (1993), en 1976, dos profesoras de 
sordos y un señante nativo emprendieron un proyecto para consignar gráficamente el léxico del LESCO. Parece ser que estas personas pasaron un tiempo en Estados Unidos y, tras haber estado en contacto profundo con la lengua de señas estadounidense, introdujeron muchos préstamos de esta en LESCO.

Dado el liderazgo, entre los jóvenes sordos, del señante que formó parte de este grupo, se produjo la aceptación generalizada de las señas extranjeras y el reemplazo de muchas de las autóctonas. Así se explicaría la diferenciación entre lo que Woodward (1992) denominó el LESCO original (OLESCO) y el LESCO nuevo (NLESCO), evidenciada en un contraste generacional entre los sordos mayores de 30 años (señantes de OLESCO) y los menores de 30 años (señantes de NLESCO). El cambio fue abrupto y radical, al punto de que ya en 1980 el diccionario de López (s.f.) recogía las señas de NLESCO.

A pesar de que, según Retana (1993), existe conciencia en la comunidad sorda de que el LESCO es distinto al ASL, Woodward (1992) señala que el NLESCO de las nuevas generaciones comparte más léxico con la lengua de señas estadounidense (ASL) que con el OLESCO. De hecho, según los cálculos de este autor, más del doble del vocabulario básico del NLESCO fue tomado directamente del ASL y sustituyó al del OLESCO en menos de treinta años ${ }^{7}$. Hasta donde sabemos, la variedad OLESCO, la lengua autóctona creada por las personas sordas en Costa Rica, ha venido retrocediendo desde hace varias décadas, sin que haya sido descrita ni documentada, de modo que se podría catalogar como en grave peligro ${ }^{8}$.

Cuadro 1

Estados de vitalidad de las lenguas en peligro en Costa Rica según lo informado por diversos autores

\begin{tabular}{|c|c|c|c|c|}
\hline Lengua & Margery (1993c) & $\begin{array}{l}\text { Quesada Pacheco } \\
\text { (2008a) }\end{array}$ & $\begin{array}{l}\text { Sánchez Avendaño } \\
\text { (2009a) }\end{array}$ & Otros autores \\
\hline bribri & declinación & declinación & declinación & \\
\hline boruca & obsolescencia & extinción & $\begin{array}{l}\text { obsolescencia- } \\
\text { extinción }\end{array}$ & $\begin{array}{l}\text { extinción(Quesada 2000a, } \\
\text { 2001-2002, 2007; Quesada } \\
\text { Pacheco 2009; Castro 2008) }\end{array}$ \\
\hline buglere & declinación & declinación & $\begin{array}{l}\text { No existen datos } \\
\text { censales }\end{array}$ & $\begin{array}{l}\text { declinación-obsolescencia } \\
\text { (Quesada 2008a) }\end{array}$ \\
\hline cabécar & declinación & declinación & declinación & \\
\hline $\begin{array}{l}\text { inglés criollo } \\
\text { limonense }\end{array}$ & & resistencia & $\begin{array}{l}\text { No existen datos } \\
\text { censales }\end{array}$ & $\begin{array}{l}\text { declinación (Umaña 1991; } \\
\text { Spence 1997, 2001; Winkler } \\
\text { 2000; Herzfeld 1994, } 2002, \\
\text { 2011; Zimmer 2011) }\end{array}$ \\
\hline $\begin{array}{l}\text { lengua de señas } \\
\text { costarricense } \\
\text { "original" } \\
\text { (OLESCO) }\end{array}$ & & & $\begin{array}{l}\text { No existen datos } \\
\text { censales }\end{array}$ & $\begin{array}{l}\text { declinación-obsolescencia } \\
\text { (Woodward 1992) }\end{array}$ \\
\hline malecu & declinación & declinación & declinación & $\begin{array}{l}\text { declinación (Constenla 1988, } \\
\text { Sánchez Avendaño 2011) }\end{array}$ \\
\hline nove & resistencia & resistencia & $\begin{array}{l}\text { declinación } \\
\text { (en Costa Rica) }\end{array}$ & $\begin{array}{l}\text { declinación (Camacho 1996), } \\
\text { resistencia (Quesada Pacheco } \\
\text { 2008c, Murillo 2008) }\end{array}$ \\
\hline térraba & obsolescencia & extinción & extinción & $\begin{array}{l}\text { obsolescencia-extinción } \\
\text { (Portilla 1986, Constenla } \\
\text { 2007a) }\end{array}$ \\
\hline
\end{tabular}


El cuadro 1 resume la información expuesta acerca del estado de vitalidad de las lenguas de Costa Rica en peligro. Empleamos la terminología de Bauman (1980) con el fin de homogeneizar la tipología.

\section{Caracterización del estado de vitalidad y de documentación de las lenguas minoritarias de Costa Rica de acuerdo con los parámetros de la UNESCO}

Basándonos en los datos disponibles para cada una de las lenguas - pese a que algunos de ellos son sumamente exiguos, fragmentarios e incluso de naturaleza impresionista- y en los trabajos panorámicos que se ocupan del estado de varios de los idiomas, a continuación se caracteriza la situación de las lenguas en peligro en Costa Rica de acuerdo con los nueve criterios y la escala de puntajes de la UNESCO (2003) ${ }^{9}$. En este modelo, seis de los factores se refieren a la vitalidad, dos a las actitudes lingüísticas y uno a la urgencia de la documentación.

\subsection{Factores relacionados con la vitalidad de las lenguas}

\subsubsection{Transmisión intergeneracional}

Para este factor, se propone una escala de seis grados: a salvo, insegura, definitivamente en peligro, en peligro severo, en peligro crítico y extinta. Con base en los datos publicados (véase particularmente Sánchez Avendaño 2009a), se puede considerar que el nove y el cabécar se encuentran en una situación insegura, ya que, si bien la transmisión intergeneracional en principio continúa activa en la mayoría de los hogares (véase Quesada Pacheco 2008c para el nove), al parecer está mermando, sobre todo en algunas localidades (como sería el caso del cabécar en Ujarrás, según datos de Bozzoli 1986, y el de los noves de Conte Burica, según lo anotado por Camacho 1996).

El malecu, el bribri y el inglés criollo limonense podrían catalogarse como definitivamente en peligro: en una buena parte de los hogares no están siendo adquiridos por los niños (véanse Bozzoli 1986 para el bribri; Spence 1997, Winkler 2000 y Zimmer 2011 para el criollo; Sánchez Avendaño 2011 para el malecu, y Sánchez Avendaño 2009a para datos de todos los grupos indocostarricenses). El OLESCO se clasificaría como en severo peligro $o$ en peligro crítico, en vista de que los únicos usuarios constituirían una minoría de adultos mayores, si bien cabe destacar que se trata de información preliminar y que urge llevar a cabo trabajo de campo. Por último, el térraba y el boruca deberían clasificarse como extintos, pues la transmisión intergeneracional cesó hace décadas (véanse Portilla 1986 y Constenla 2007a para el térraba, y Quesada Pacheco 1995a, 1995b, 1997b, 2008c, 2009, Quesada 2000 y Castro 2008 para el boruca), mientras que el buglere estaría en peligro severo según lo informado por Quesada (2008a).

\subsubsection{Número absoluto de hablantes}

Si bien el criterio del número absoluto de hablantes no se desglosa en niveles en el modelo de la UNESCO, según los datos analizados en Sánchez Avendaño (2009a), podría decirse que todas las lenguas amerindias de Costa Rica se encuentran en una situación crítica, al menos en lo que respecta a las poblaciones asentadas en el territorio nacional.

Ciertamente, si se toma en cuenta que el nove es la lengua indígena con mayor número de hablantes en Panamá (Quesada Pacheco 2008c, Quesada y Vejerano 2010) y que el inglés criollo de Limón está estrechamente relacionado con otras variedades del Caribe (Herzfeld 2002, 2008), entonces habría que destacar que estas dos lenguas se encuentran, de forma global, en una buena situación, pese a que la cifra de hablantes sea reducida en Costa Rica, sobre todo en el caso del nove. En cuanto al térraba, habría que indicar que existe una variedad geolectal de la misma lengua en Panamá, conocida con el nombre de teribe (Constenla 2007a), y que esta se suele caracterizar como en un estado de conservación mejor que el del térraba (Quesada Pacheco 2008a). 
Por último, se desconoce el número de usuarios de la lengua de señas costarricense, pero sin duda alguna la adquisición de la variedad NLESCO ha aumentado desde hace, por lo menos, unas cuatro décadas. No obstante, la población sorda usuaria del idioma de señas no deja de ser un grupo minoritario (y minorizado) en el país. Al parecer, la variedad OLESCO, por su parte, debería clasificarse como en situación crítica.

\subsubsection{Proporción de hablantes con respecto a la población total de los grupos}

Para este factor se propone la misma escala que para el factor de transmisión intergeneracional. Con base en los datos analizados por Sánchez Avendaño (2009a), se puede considerar que el nove y el cabécar se encuentran en una situación insegura, ya que se reporta que, si bien ambos son hablados por la mayoría de la población, no todos los niños los están adquiriendo o los hablan en el presente. Empero, a juzgar por el análisis de Quesada Pacheco (2008c) y de Murillo (2008), cabría considerar que el nove está a salvo por el momento.

El malecu, el bribri, el buglere y el inglés criollo limonense podrían catalogarse como definitivamente en peligro, si bien la situación varía mucho en cada uno de los poblados (véase Sánchez Avendaño 2011 para un recuento pormenorizado de la situación del malecu y Sánchez Avendaño 2009a para datos de todas las lenguas amerindias). En todo caso, en general, la mayoría de la población adulta todavía maneja estos idiomas (véanse Bozzoli 1986 para el bribri, Spence 1997 y Zimmer 2011 para el criollo, Constenla 1988 y Sánchez Avendaño 2011 para el malecu, Quesada 2008a para el buglere, y Sánchez Avendaño 2009a para datos de todos los grupos indocostarricenses).

Por su parte, el OLESCO debería clasificarse como en peligro crítico, por las razones ya aducidas. El boruca también estaría en peligro crítico, pues solo algunas pocas personas ancianas muestran un manejo reducido de la lengua (Castro 2008; Quesada Pacheco 1995a, b). Por último, el térraba debería clasificarse como extinto, ya que, al parecer, no quedan ni siquiera semihablantes (Constenla 2007a).

\subsubsection{Dominios funcionales ya existentes o tradicionales}

Para el factor de los dominios de uso, referido a los temas, el lugar y con quién se emplea el idioma, se propone la siguiente escala: uso universal, igualdad multilingüe (diglosia), disminución de dominios, dominios limitados o formales, dominios altamente limitados y extinción.

El cabécar, el nove y el criollo limonense, en la mayoría de los casos, así como el bribri en algunas comunidades, mostrarían disminución de dominios en el presente, si bien quizás queden resabios de la situación sociolingüística del pasado caracterizada por el uso universal o la igualdad multilingüe, particularmente en lo que respecta al nove (Quesada Pacheco 2008c, Murillo 2008). Día tras día, estos idiomas pierden esferas de uso tradicionales, lo que incluye el retroceso de su empleo en la comunicación familiar (véanse Spence 1997, 2001 y Zimmer 2011 para el criollo, y Margery 1993c para una discusión general).

Por su parte, el malecu mostraría dominios limitados: se emplea en los hogares en los que residen los ancianos y personas mayores, y quizá en algunos encuentros culturales, pero, a pesar de que muchos adultos pueden entenderlo y hablarlo, no siempre lo emplean (véase Sánchez 2011 para un estudio detallado al respecto). Al parecer, el boruca ya no conserva ninguna esfera de uso, a no ser por un empleo residual en festividades tradicionales (Rojas 1988), de modo que estaría extinto o, en el mejor de los casos, mostraría dominios altamente limitados. El térraba se consideraría una lengua extinta también según este parámetro (Portilla 1986).

El NLESCO es de uso universal entre señantes competentes, pero muchas personas sordas no han tenido la posibilidad de adquirir 
la lengua o manejan variedades más cercanas al español signado que al LESCO; además, si bien las leyes establecen la obligatoriedad de contar con individuos competentes en este idioma en las instituciones públicas, no es seguro que ello se cumpla en todas las instancias. Por último, se desconoce la situación del OLESCO y del buglere a este respecto.

\subsubsection{Dominios funcionales nuevos y presencia en los medios de comunicación masiva}

Para el criterio de respuesta a los nuevos dominios y medios de comunicación masiva, se proponen los siguientes niveles: dinámico, robustolactivo, receptivo, resistente, mínimo e inactivo. Este parámetro se refiere al surgimiento de nuevos ámbitos de utilización de la lengua conforme cambian las condiciones de vida.

Todas las lenguas minoritarias de Costa Rica, con la notable excepción del NLESCO (la cual aparece en traducción simultánea en algunas ediciones de los noticieros y en grado variable en otros programas dependiendo de cada televisora), tendrían que catalogarse en el nivel mínimo e, incluso, inactivo, dado que o solo se emplean en algunos pocos dominios nuevos o de plano no se utilizan en ninguno (véase Margery 1993c para una discusión general). Las radioemisoras locales ubicadas en los territorios indígenas, por ejemplo, aparentemente transmiten muy poco en las lenguas vernáculas, si es que todavía lo hacen.

Puede haber surgido algún dominio funcional nuevo, como ocurre con las representaciones teatrales en las comunidades malecus, pero este suele estar restringido al ámbito del turismo (Sánchez Avendaño 2011). El empleo de las lenguas vernáculas como código secreto para la comunicación intraétnica con el propósito de excluir a quienes no pertenecen al endogrupo parece ser el único ámbito de uso "nuevo" común a varios pueblos (véase Sánchez Avendaño 2011 para los malecus y Castro 2008 para los borucas).

En lo que respecta al ámbito educativo, existe un programa de educación bilingüe en los territorios indígenas, consistente en enseñar dos asignaturas (una de lengua vernácula y otra de cultura tradicional) por cinco lecciones a la semana (de 40 minutos cada una) en el nivel de primaria, pero las demás asignaturas se imparten en español. En términos generales, la inclusión e implementación eficaz de las clases de lengua y cultura vernáculas en el currículo sigue enfrentándose con serios escollos, tales como carencia de materiales didácticos adecuados, nula o escasa formación pedagógica de los maestros encargados y desinterés por parte de miembros de las comunidades (véanse Rojas 1997-1998, 2002, 2006; Vásquez 2008; Ovares y Rojas 2008 y Quesada 2008b para un recuento general de las iniciativas y de los problemas; Sánchez Avendaño 2012 para un estudio particular sobre las características de la clase de lengua malecu; Castro 2008 para el caso boruca, y Lamounier 2009 para una descripción de las características y problemática de la educación en los territorios bribris y cabécares).

El nuevo modelo educativo bilingüe que promueve el Ministerio de Educación Pública en las escuelas que atienden a niños sordos incentiva el empleo del NLESCO como lengua de instrucción, pero es difícil determinar en qué medida esta situación es generalizada o depende exclusivamente de la competencia de los maestros en el idioma de señas. Por su parte, el inglés limonense no se ha incorporado hasta la fecha al currículo escolar de la provincia en la que reside la mayor cantidad de hablantes.

Así las cosas, en lo que atañe a la educación y partiendo de las dos dimensiones que, según la UNESCO, determinan las consideraciones sobre el puntaje (hasta qué nivel y con qué amplitud a lo largo del currículo se usa la lengua en peligro), habría que catalogar la situación de las lenguas indocostarricenses como mínima y la del inglés criollo como inactiva.

\subsubsection{Materiales educativos y para la alfabetización}

En lo concerniente al factor de los materiales educativos y para la alfabetización, la 
UNESCO propone puntajes y una caracterización para asignarlos, pero no etiquetas para los niveles. Para casi todas las lenguas indocostarricenses, se podría asignar un puntaje de 3 o 2 (en una escala de 5), en el entendido de que existen materiales escritos en todas ellas y, en principio, los niños tienen acceso a estos en las escuelas e incluso aprenden a escribir los idiomas vernáculos en la clase. Sin embargo, la mayor parte del material disponible está constituido por muestras del arte verbal tradicional (por lo general, variedades formales y "especiales" de las lenguas, como hablas rituales o de temática mítica, o bien registros formalmente alejados de las variedades coloquiales cotidianas), de modo que se podría considerar que tales materiales poseen, sobre todo, un valor simbólico (por lo demás, sumamente relevante en términos de documentación del patrimonio lingüísticocultural) y resultan de utilidad inmediata tan solo para unos cuantos miembros de los grupos (grado 2 en la escala de la UNESCO), quienes tendrían la competencia lingüística y cultural suficiente para comprenderlos y apreciarlos.

Paradójicamente, los individuos con mayor competencia para entender tales materiales normalmente no están acostumbrados a leer y escribir la lengua autóctona (si es que están alfabetizados), mientras que los niños y jóvenes, quienes usualmente han recibido clases de lecto-escritura de los idiomas vernáculos, por lo general, carecerían de la competencia suficiente para poder apreciar y entender los textos a cabalidad.

Con excepción del periódico en bribri Biyö 'chókna me, del que se editaron nueve números de marzo a noviembre de 1978, y de las traducciones de artículos periodísticos del español al boruca realizadas por Maroto (1999) en la década de 1970, no parecen existir textos escritos sobre temas distintos a las temáticas de la tradición oral. En el caso del inglés limonense, si bien se han publicado textos relativos a la tradición oral (por ejemplo, Anglin 2002 y Britton 2008), estos suelen estar escritos en una variedad de inglés formal y, por ende, alejada del basilecto.
En cabécar existe un cuerpo de material didáctico diseñado específicamente para ser utilizado en las aulas de primaria de los territorios cabécares: la serie de seis libros (uno para cada grado) Sa ñayuwä. Sa siwạwa. Estudiemos cabécar (Hedström-Rojas y Martínez 2005a, 2005b; Fernández et al 2005a, 2005b; Fernández y Hedström-Rojas 2011a, 2011b) y el texto de lectura Siböte i-ka dieyá. El banquete de Sibö (Fernández y Hedström 2011c). De igual forma, Quesada Pacheco (2009) se refiere a la existencia de textos didácticos para el aprendizaje del boruca en todos los niveles de primaria (serie con el nombre Hablamos boruca) y a una "gramática didáctica interactiva sonora" que también se distribuirá en la escuelas borucas. Así, la existencia de materiales didácticos escolares para estas dos lenguas indicaría que su situación, a este respecto, aventaja a la de las demás.

Resulta fundamental destacar que todas las lenguas indocostarricenses cuentan con una ortografía práctica (véanse Margery 1985b, 1989a para el cabécar; Margery 1982a para el bribri; Constenla 1998 para el malecu; Constenla 2007a para el térraba; Constenla y Maroto 1979 para el boruca; Quesada Pacheco 2008a para el nove, y Margery 1996 para el buglere ${ }^{10}$ ) y que para muchas también existen abecedarios ilustrados para su uso en las escuelas de los territorios indígenas (véanse Constenla y Castro 1994 y Proyecto Río Frío et al 2011c para el malecu, Jara 1986 para el boruca, Constenla 1992 para el bribri, Margery 1986c para el cabécar, Constenla 1986 para el térraba, y Constenla y Bejarano 1994 para el nove) y textos para la enseñanza de la lecto-escritura (véanse García 1986 y Gudiño 1994 para el bribri, y Montezuma 1995 para el nove).

\subsection{Actitudes y políticas lingüísticas}

\subsubsection{Políticas y actitudes gubernamentales y oficiales}

La UNESCO propone el factor de actitudes y políticas gubernamentales e institucionales, incluyendo el uso y estatus oficial de los idiomas, como uno de los parámetros que influye 
directamente en las actitudes lingüísticas de la comunidad. Los niveles son los siguientes: apoyo equitativo, apoyo diferenciado, asimilación pasiva, asimilación activa, asimilación forzada y prohibición.

En el caso de Costa Rica, habría que considerar que el grado de apoyo a las lenguas minoritarias corresponde al denominado asimilación pasiva, debido a que, si bien la Constitución Política (título VII, artículo 76, modificado por la Ley 7878 de 1999) establece que "el Estado velará por el mantenimiento y cultivo de las lenguas indígenas nacionales", para toda interacción con la administración pública se requiere utilizar el español, así que no se aplica ni siquiera el principio de territoriedad, según el cual el empleo de la lengua minoritaria se restringe a la administración en el territorio donde se ubica la comunidad de hablantes (Arel 2002). De hecho, el mismo artículo solo reconoce el estatus de lengua oficial nacional al español. Por lo demás, en la Constitución no se menciona el inglés limonense, mientras que solo recientemente el LESCO fue reconocido, mediante la Ley 9049, como "lengua materna de la comunidad sorda", lo que implica que el Estado debe garantizar la posibilidad de educación de los niños en este idioma.

En todo caso, justo es reconocer que en los últimos años se ha producido un cambio radical en las políticas lingüísticas del gobierno en relación con las comunidades etnolingüísticas minoritarias, de modo que, al menos en el papel, se reconoce la importancia de conservar el patrimonio idiomático conformado por las lenguas amerindias y se incentiva su inclusión en el aparato educativo oficial en el nivel de primaria (Rojas 1997-1998, 2002; Quesada Pacheco1999-2000), situación radicalmente opuesta a la política lingüística oficial de asimilación activa, asimilación forzada y prohibición seguida décadas atrás (Quesada Pacheco 1999-2000).

\subsubsection{Actitudes de los miembros de las comunidades etnolingüísticas}

Para este criterio, no se proponen términos para los distintos niveles, sino solo los puntajes y su interpretación. Es claro que la valoración de este parámetro requiere de trabajo de campo en cada una de las comunidades. Lamentablemente, este solo se ha llevado a cabo de modo sistemático en el caso del malecu (Constenla 1988, Sánchez Avendaño 2011), el térraba (Portilla 1986) y el criollo limonense (Zimmer 2011), así que no es posible asignar puntaje por el momento, ni siquiera de modo preliminar, para el bribri, el cabécar, el nove, el buglere ni el LESCO. Eso sí, muy posiblemente las actitudes hacia la lengua de señas (en este caso hacia su extensión y conservación) sean muy positivas en la comunidad sorda, según hemos podido apreciar en distintas actividades públicas.

Para el malecu, podría decirse que el puntaje oscila entre 4 y 3 : cuando se les pregunta, la mayoría de los malecus declaran apoyar la conservación de su lengua vernácula, pero también informan que muchos individuos se muestran indiferentes o la rechazan (Sánchez Avendaño 2011). En el caso del inglés limonense, los datos preliminares de Umaña (1991), Simms (1990) y Herzfeld (1994, 2002) apuntan a que existe una valoración ambigua o incluso negativa (como cuando se califica de "mal inglés"), la cual, empero, tiende a tornarse mucho más positiva en los últimos tiempos (Zimmer 2011, Herzfeld 2011), así que el puntaje podría ser de 2 o 3 .

La investigación de Portilla (1986) con los últimos hablantes y semihablantes del térraba, así como con sujetos monolingües en español, recoge actitudes de menosprecio hacia esta lengua, pese a que todavía en ese entonces parecía concebirse como marca de identidad étnica y pese a que los sujetos monolingües en español declararon sentir mayor interés por su conservación que los bilingües, quienes tendían a mostrar actitudes de menor aprecio por el idioma autóctono. De este modo, las actitudes hacia su revitalización posiblemente oscilen entre 1 y 2 .

En lo relativo a las actitudes de los borucas hacia su lengua ancestral, Quesada (2000a) informa que, en particular en los jóvenes, estas son de indiferencia e incluso vergüenza, además de que existe una creencia muy extendida entre 
ellos de que la lengua de sus antepasados no es adecuada para adaptarse al mundo moderno. Así, según este autor, la lengua es vista como irrelevante y propia de los ancianos. Castro (2008) también expone que predomina la actitud de vergüenza hacia la lengua boruca.

Por su parte, Quesada Pacheco (1995a,b) señala que ha surgido recientemente en los jóvenes borucas un sentimiento de identidad étnica, el cual se manifiesta en orgullo por la adscripción a la etnia y seguridad por el origen indígena, además de mayor práctica de las costumbres tradicionales. Según este académico, en lo concerniente a las actitudes hacia la revitalización de la lengua autóctona, los mayores se muestran indiferentes y hasta contrarios a las nuevas políticas educativas, mientras que los jóvenes se lamentan de la pérdida de su idioma vernáculo y se muestran más interesados en su rescate.

Como se puede apreciar, debido a que no se ha realizado un estudio específico y detallado de las actitudes lingüísticas hacia la revitalización del boruca, no es posible determinar cuál de las actitudes consignadas por los investigadores predomina o si todas coexisten de modo conflictivo. En cualquier caso, el puntaje correspondiente a la valoración de la actitud de los borucas con respecto a la revitalización de su lengua vernácula sería de 3 o 2 .

\subsection{Documentación y descripción}

El último factor considerado por la UNESCO es la urgencia de documentación de una lengua, que incluye la determinación de la calidad y del tipo de materiales lingüísticos existentes. Siguiendo a Himmelmann (2006), podemos distinguir dos tipos de trabajo lingüístico a este respecto: la documentación (recopilación y preservación de datos lingüísticos primarios que conforman un corpus estructurado $\mathrm{y}$ accesible por medio de anotaciones y comentarios $^{11}$ ) y la descripción (sistematización acerca del funcionamiento del sistema de la lengua partiendo de un marco teórico particular).

Podría afirmarse que la situación de las lenguas minoritarias de Costa Rica es, en lo relativo a este factor, notablemente más positiva que en lo que respecta a los demás parámetros, en vista de que, para todas las lenguas indocostarricenses, existen diccionarios o al menos listados léxicos extensos (publicados o en fase de preparación) y descripciones gramaticales y fonológicas, así como textos anotados. Además, en algunos casos existen estudios de análisis del discurso y pragmática.

Así las cosas, la valoración del estado de documentación y descripción del cabécar, el bribri, el nove y el malecu podría considerarse buena. El térraba debería ser valorado del mismo modo, a pesar de que fue posible registrar muy pocos textos tradicionales debido al avanzado estado de desplazamiento con que lo encontraron los lingüistas que empezaron a ocuparse de su descripción hace unas cuatro décadas. Del buglere existen descripciones de algunos aspectos de su gramática y de su sistema fonológico, pero no una gramática comprehensiva; no obstante, se dispone de un amplio corpus anotado de textos tradicionales, así que su documentación podría valorarse como buena. Lo mismo habría que decir acerca del boruca, lengua de la que existen bosquejos gramaticales y fonológicos, y una gramática con fines didácticos, además de un corpus representativo de textos tradicionales, bien anotado y adecuado para elaborar más estudios. La valoración sería, entonces, también en este caso, de buena.

Cabe destacar, además, que, en los últimos años, quienes se han ocupado de documentar las manifestaciones discursivas tradicionales indocostarricenses se han preocupado por acompañar las publicaciones de los textos (transcritos todos en las ortografías prácticas respectivas de cada lengua, con traducción literal anotada con comentarios lingüísticos y etnográficos, y con traducción libre) con discos compactos con las grabaciones de audio. Por ende, si bien aún no se dispone de un repositorio digital de los textos documentados, al menos sí están disponibles algunas de las grabaciones del bribri (Constenla 2006, Jara y García 2008), el boruca (Constenla y Maroto 2011, Constenla 2011) y el malecu (Constenla y Castro 2011). 
Menos positiva es la evaluación para el inglés criollo limonense, sobre el cual existen descripciones fonológicas y gramaticales detalladas (así que la descripción se valoraría como buena), pero no un diccionario publicado ni textos anotados de la variedad basilectal, con excepción de cuatro textos sin anotación recogidos en Britton (2008), de los cuales solo uno se incluye en versión digital en el disco compacto que acompaña el libro. De este modo, en cuanto a su documentación, este idioma recibiría una valoración de lengua prácticamente no documentada.

Del NLESCO existe un breve diccionario, pero muy pocas descripciones de su estructura; sin embargo, en la actualidad se está desarrollando un ambicioso proyecto cuyo producto pretende ser, además de una descripción básica del idioma y un diccionario en línea, la conformación de un amplio corpus discursivo ${ }^{12}$. Por consiguiente, la descripción y documentación de la variedad nueva de la lengua de señas costarricense (NLESCO), aunque reciba una valoración de inadecuada o inexistente en este preciso momento, sin duda pasará al estado de buena cuando el proyecto en marcha esté concluido. No obstante, la variedad OLESCO permanece sin ser documentada ni descrita, lo cual resulta lamentable dado su alto grado de declinación ${ }^{13}$.

En términos generales, pese a que se debe subrayar la ingente cantidad y la gran calidad de los trabajos de descripción de las lenguas en peligro en Costa Rica, como resultado de una labor profesional ininterrumpida llevada a cabo por lingüistas sobre todo nacionales, también debe señalarse que tales descripciones responden a los marcos teóricos con base en los cuales se han recogido y analizado los datos; a saber: el estructuralismo norteamericano, el generativismo chomskiano, el funcionalismo tipológico y el funcionalismo sistémico, principalmente.

En este sentido, siguiendo a Himmelmann (2006), la labor descriptiva de las lenguas de Costa Rica se ubicaría en lo que este lingüista denomina el formato de la gramática-diccionario, basado en la concepción de la lengua como sistema de reglas y oposiciones, en el cual se suelen producir gramáticas (o descripciones específicas de las reglas morfosintácticas y fonológicas de los idiomas) y diccionarios (compendios de pares de forma-significado), a veces acompañados de textos que sirven como ejemplos.

De acuerdo con Himmelmann, los problemas de este formato son básicamente cuatro: generalmente no se documentan muchas de las prácticas comunicativas propias de una comunidad de habla ${ }^{14}$; las gramáticas y los diccionarios incluyen abstracciones basadas en determinados procedimientos de análisis, los cuales no son verificables ni replicables si no se cuenta con el corpus; las gramáticas habitualmente solo se ocupan de temas conocidos y comprendidos en el momento en el que se escriben; y las descripciones gramaticales de este tipo (e incluso muchas veces los diccionarios) frecuentemente son de poca utilidad para la comunidad de habla, los maestros y los investigadores que no son lingüistas.

Por este motivo, y en particular cuando se habla de lenguas en peligro, la documentación es el paradigma en boga en la actualidad, pues se enfatiza la necesidad de recoger, anotar (incluir traducciones literales, glosas interlineales, comentarios gramaticales y etnográficos) y preservar un corpus extenso de datos lingüísticos primarios de la mayor cantidad posible de registros, variedades y eventos comunicativos distintos, grabados preferiblemente en ambientes naturales, con el fin de que puedan ser utilizados para futuros trabajos de descripción, teorización y revitalización de los idiomas documentados.

A este respecto, ciertamente el trabajo de documentación del arte verbal tradicional codificado en las lenguas indocostarricenses debe calificarse como sobresaliente. Los lingüistas del país se han ocupado de recoger, transcribir, anotar y traducir corpus representativos de diversas manifestaciones de la tradición oral de los bribris (particularmente de la variedad de Coroma), los malecus (en especial de la variedad de Margarita), los noves (particularmente de las poblaciones de Panamá), los buglere y los borucas ${ }^{15}$. También se han recogido muestras de registros y variedades "especiales" (en particular, el habla ritual y el habla infantilizada) 
del bribri. Sin embargo, en general, se puede afirmar que no se han documentado otros eventos comunicativos, incluyendo el habla coloquial de la interacción cotidiana. Tratándose de lenguas altamente amenazadas, urge ampliar, por lo tanto, esta labor de documentación.

\section{Conclusiones}

Los trabajos panorámicos acerca de la vitalidad de las lenguas costarricenses en peligro, así como las publicaciones que se ocupan de una lengua o de un fenómeno de una lengua en particular, nos permiten esbozar la situación general de declinación, obsolescencia y extinción que expusimos en los apartados anteriores.

Empero, no obstante la importancia de estas caracterizaciones generales, se requieren estudios específicos y detallados de la situación sociolingüística de cada comunidad que nos brinden una visión completa de los siguientes aspectos: el estado de conservación de cada lengua por grupos generacionales y localidades, la determinación de la esferas de uso y la caracterización de los tipos de hablantes y de ser posible- su cuantificación aproximada. Asimismo, es fundamental llevar a cabo un recuento pormenorizado del devenir histórico y de los factores que han incidido en el abandono de los idiomas, al estilo de la descripción acerca del proceso de desplazamiento del malecu presentada en Sánchez Avendaño (2011).

En Costa Rica existe ya una larga tradición lingüística de descripción y de documentación de las lenguas costarricenses. Todas las lenguas han recibido atención de los lingüistas, con la lamentable excepción de la lengua de señas costarricense en sus distintas variedades, la cual ha sido la menos descrita -al menos de forma especializada- y la menos documentada de todos los idiomas del país, situación que dichosamente ha comenzado a cambiar.

En cuanto a la labor de documentación, hasta el momento ha primado la recopilación y procesamiento de textos narrativos y poéticos tradicionales, sin duda alguna debido a su alto valor simbólico tanto para el estudio del arte verbal tradicional de los pueblos como para el resguardo del patrimonio cultural de la humanidad. Sin embargo, para un estudio lingüístico más completo de las lenguas y para futuros proyectos de revitalización, se requiere intensificar la documentación de variedades discursivas coloquiales y de eventos y registros idiomáticos de distinta naturaleza.

\section{Anexo}

A continuación se detalla el estado de documentación y descripción de cada una de las lenguas contempladas en este artículo. Si bien hemos procurado ser exhaustivos en la consignación de los trabajos publicados, es posible que hagan falta algunos estudios. Salvo algunas excepciones, solo se citan tesis que no hayan sido publicadas en forma de artículos. Tampoco se consignan las publicaciones anteriores a la década de 1970, las cuales, si bien resultan muy valiosas para los trabajos de tipo diacrónico, no suelen basarse en un marco teórico-metodológico lingüístico $\mathrm{y}$, muchas veces, presentan problemas de transcripción de los datos.

Cabécar: cuenta con el diccionario más completo (Margery 1989), el cual incluye también una descripción gramatical y fonológica de corte estructuralista. Asimismo, existen descripciones de temas particulares en artículos y tesis (Bourland 1975, 1976; Margery 1982b, 1983, 1985a, 1985b, 1985c, 1986c; Bertoglia 1983), así como sistematizaciones de las etnotaxonomías en la cultura tradicional (Margery 1984, 1986b; Hernández 1992; Edwards 2006). También se han publicado textos tradicionales transcritos en la ortografía práctica con traducción literal (morfemática) y libre (idiomática) (Margery 1986a, 1995; Constenla 1996), pero ciertamente su cantidad (unos 5 textos narrativos, más algunos cantos), en comparación con la de otras lenguas indocostarricenses, es muy reducida. Existe un corpus mucho mayor de textos en cabécar con tan solo traducción libre al español (Varas y Fernández 1989a, 1989b; HedströmRojas y Martínez 2005a, 2005b; Fernández et al 2005a, 2005b; Fernández y Hedström-Rojas 2011a, 2011b; Fernández y Hedström 2011c). 
Bribri: existe un diccionario que incluye una descripción fonológica y gramatical de corte estructuralista (Margery 1982a); también se han publicado varias descripciones de la fonología y aspectos particulares de la gramática (Wilson 1970, 1974, 1984; Schlabach 1974; Constenla 1982c; Schlabach y Levinsohn 1982; DickemanDatz 1984, 1985; Amador 1986; Monge 1988; Bett 1990, 1991; Villalobos 1991, 1993; Calvo 1994; Jara 1991, 1995a, 1995b, 1995c, 2002, 2003, 2006; Sánchez Avendaño 2009b; Pacchiarotti 2010; Cruz 2010, 2011), gramáticas descriptivas y cursos para la enseñanza de la lengua (Constenla et al 1978, 1979; Constenla et al 1998; Jara y García 2009), así como estudios sobre campos léxicos particulares (Jara 1987, Cervantes 1993) y etnotaxonomías (Jiménez 1987, Rimolo 2007, Flores 2009). Además, existen estudios de corte pragmático y de análisis del discurso (Lininger 1990; Jara 1995c, 1997-1998, 1998). También existen estudios particulares sobre las variedades geolectales (Jara 2004a) y “especiales" del bribri (Constenla 1990, Cervantes 1991, Constenla y Elizondo 1994).

En cuanto a textos publicados en bribri, se encuentran muchos materiales del arte verbal, algunos sin traducción morfemática (Bozzoli 1977a, 1977b; Cervantes 1991; Sánchez y Mayorga 1994; COOPA 1996), pero también un corpus importante de textos bien anotados con traducción morfemática y libre (Jara 1993; Constenla 1996, 2006; Jara y García 2008), el cual no solo consiste en textos narrativos de naturaleza mítica o tradicional, sino que también incluye textos descriptivos y expositivos (Jara y García 2008) e incluso muestras de textos conversacionales (Jara 2004b).

Boruca: se cuenta con un diccionario (Quesada y Rojas 1999) y recopilaciones léxicas (Quesada Pacheco 1996), descripciones de la fonología y la gramática (Abarca 1988; Alvarado 1989; Rojas 1992; Quesada y Quesada 1995; Quesada Pacheco 1996, 1997-1998; Castro 2008), estudios de análisis del discurso (Rojas 1990), gramáticas descriptivas de corte didáctico (Quesada Pacheco 1995b), descripciones de campos léxicos particulares (Constenla 1977) y de eventos comunicativos especiales (Rojas 1988), así como textos con traducción morfemática y libre (Constenla y Maroto 1979/2011; Constenla 1986b, 1996, 2011a; Rojas 2005; Quesada Pacheco 1996, 1997a) y textos en boruca con tan solo traducción libre al español (Maroto 1999).

Térraba: existe un pequeño diccionario y una gramática que incluye la descripción fonológica (Constenla 2007a); también se han publicado listados léxicos y de oraciones (Portilla 1986), descripciones gramaticales (Díaz 1976, Lininger 1977, Lininger et al 1978, Constenla 1997-1998, Portilla 1999-2000) y un pequeño corpus discursivo (Constenla 1996).

Nove: existe una gramática que incluye la descripción fonológica (Quesada Pacheco 2008b). Asimismo, se han publicado descripciones gramaticales (Kopesec 1975, Smith y Zamora 1979, Payne 1982, Madrigal 1984, Murillo y Quesada 2008, Murillo 2008), fonológicas (Lininger 1981, Arosemena y Melquíades 1983, Abarca 1985) y de análisis del discurso (Arosemena y Melquíades 1975, Arosemena 1975), listados léxicos (Lininger 1982, Abarca 1985), textos tradicionales con traducción morfemática e idiomática (Constenla 1996, Quesada Pacheco 2006, Quesada y Bejerano 2010) o con tan solo traducción libre (COOPA 1997, Javilla s.f.), y textos no tradicionales con traducción libre y morfemática (Murillo y Quesada 2008). El Dr. Miguel Ángel Quesada Pacheco (comunicación personal) se encuentra preparando un diccionario. Cabe destacar, eso sí, que la gran mayoría de las publicaciones sobre esta lengua se basan en datos recogidos a hablantes de Panamá.

Buglere: existen descripciones gramaticales (Margery 1988; Jara 1989; Solís 1989; Quesada 2006, 2007, 2008a), listados léxicos (Margery 1993d), y, sobre todo, un corpus representativo de textos tradicionales con traducción morfemática y libre (Margery 1989b, 1989c, 1990a, 1990b, 1990c, 1990d, 1992, 1993a, 1993b, 1997, 1999; Margery y Rodríguez 1992; Córdoba 2001-2002).

Malecu: existe un corpus importante de textos propios del arte verbal tradicional, con traducción literal y libre (Betancourt y Constenla 1981; Constenla 1991, 1992b, 1996, 1999, 2003, 
2007, 2011b; Constenla, Castro y Blanco 1993, Constenla y Castro 2011) y textos con tan solo traducción libre al español (Mejía et al 1995, Instituto de Estudios de las Tradiciones Sagradas de Abia Yala 2000 y Proyecto Río Frío et al 2011b). Asimismo, se han publicado descripciones y análisis sobre la etnografía del habla (Constenla 1982b), la onomástica (Constenla 1995) y la etnoornitología vernácula (Pizarro 2005). También existe una breve descripción del sistema de parentesco ancestral (Bozzoli 1972). En cuanto a la vertiente descriptiva, existen trabajos acerca de los componentes morfosintáctico, fonológico y léxico (Constenla 1975, 1982a, 1983, 1985, 1986a, 1986b, 1990, 1992a, 1995, 1998; Sánchez 1979, 1984; Álvarez et al 1979; Smith 1979; Proyecto Río Frío et al 2011a; Krohn 2012). El Dr. Adolfo Constenla (comunicación personal) se encuentra preparando un diccionario.

Inglés criollo limonense: existen descripciones detalladas de la fonología y la gramática (Wolfe 1970; Wright 1974, 1975, 1982; Dickeman 1985b; Masís y Mora 1985; Portilla 1993, 1995, 1996, 1997, 2004, 2005, 2010; Herzfeld 2002). También existen compilaciones de cuentos que incluyen algunos textos en criollo (Anglin 2002, Britton 2008), pero, al no haber sido realizadas por lingüistas ni responder a un interés documental, es frecuente que se transcriban los textos en ortografía inglesa estándar o que no se registren con detalle los rasgos basilectales.

LESCO: del NLESCO, por el momento, tan solo existe un diccionario básico (López, s.f.) y una monografía sobre el aspecto verbal (Retana 1993).

\section{Notas}

1. Deseo expresar mi agradecimiento a Luis Esteban Artavia Tencio por la acuciosa revisión de las referencias bibliográficas, a la M.L. Patricia Guillén Solano por la revisión filológica y al M.L. Henry Angulo por la revisión de la traducción del resumen al inglés.

2. Según el modelo de la vitalidad etnolingüística propuesto por Giles et al (1977), son tres las variables estructurales que posiblemente influyan más en la vitalidad etnolingüística de un grupo: el estatus (económico, social, histórico y lingüístico), la demografía (el número de miembros del grupo y su distribución en el territorio) y el apoyo institucional (representación formal e informal en las instituciones nacionales, regionales o comunitarias, y en los medios de comunicación masiva).

3. En el modelo elaborado por Bauman (1980), se propone una tipología de estados de conservación, los cuales abarcan el florecimiento, la resistencia, la declinación, la obsolescencia y la extinción. Estos estados se determinan con base en los siguientes criterios: proporción de hablantes según sus edades y grado de bilingüismo, relación entre el número de hablantes y los cambios en la población total de la comunidad, fluidez de los hablantes jóvenes, transmisión de la lengua en el hogar, grado de preferencia de la lengua en diferentes situaciones, grado de asimilación de la lengua minoritaria a las estructuras de la lengua dominante, grado de flexibilidad de la lengua para ajustarse a la cultura cambiante de la comunidad, y grado de alfabetización en la lengua vernácula.

4. Según Retana (1993), el primer dato que se conoce sobre el uso de la lengua de señas por parte de la población sorda costarricense se remonta a 1939, cuando se fundó la Escuela de Enseñanza Especial Fernando Centeno Güell. En esta institución, se dio el caldo de cultivo para que los jóvenes sordos de San José entraran en contacto y se comunicaran con un sistema lingüístico señado, al menos durante los recreos. La aparición de organizaciones que aglutinan a las personas sordas, para realizar actividades deportivas, culturales y recreativas, y posteriormente la creación de instancias encargadas de velar por los intereses de la comunidad dieron pie a que surgiera un sentimiento de identidad y cohesión, que conducirá luego a la propuesta de la existencia de una "comunidad sorda" y de una "cultura sorda". Es claro que en estos casos la lengua de señas actúa como un símbolo ideológico con la fuerza suficiente para unir a las personas sordas en torno a causas comunes y para construir una etnicidad basada en la posesión de una lengua distinta a la del grupo oyente.

5. En estas lenguas, el morfema pluralizador únicamente se emplea con sustantivos referidos a seres humanos y algunos seres sobrenaturales. Ambas son lenguas de sistema ergativo-absolutivo y marcan este caso por medio de diversas partículas que se posponen a la frase nominal a la que se le 
asigna el ergativo. Por último, lo tradicional en estas lenguas ha sido el orden sustantivo+demostrativo (Constenla et al 1998, Margery 1989a).

6. Todos los símbolos fonéticos empleados en este trabajo corresponden a los del Alfabeto Fonético Internacional (AFI).

7. Utilizando el método glotocronológico para determinar el grado de parentesco entre las lenguas, Woodward (1992) encontró un 63,3\% de cognados entre el NLESCO y el ASL, por lo que ambas se catalogarían como lenguas distintas -según las premisas de esta teoría- pero muy cercanas históricamente. Por su parte, únicamente se encuentra un $41,8 \%$ de cognados entre el OLESCO y el NLESCO, lo que implica que son lenguas distintas y no muy cercanas, sobre todo si se toma en cuenta que las señas cognadas entre el OLESCO y el ASL (idiomas relacionados de forma muy distante a través de la lengua de señas española y la lengua de señas francesa) es de $25,5 \%$ y que la mayoría de estas fueron retenidas por el NLESCO (por ejemplo, las señas para 'pájaro', 'niño', 'huevo', 'bueno' y 'viejo'). Así, en realidad, el porcentaje de señas del NLESCO que provienen solo del OLESCO es de $16,3 \%$, mientras que las señas que son propias del NLESCO y que no tienen relación ni con el ASL ni con el OLESCO es de 20,4\%.

8. A este respecto, Nonaka (2004) llama la atención sobre el olvido de las lenguas de señas "indígenas" y "originales" (en contraste con las "nacionales") muy vulnerables a desaparecer y por lo general poco descritas- en las discusiones acerca de los idiomas amenazados, pese a que estas pueden proporcionar información valiosa sobre tipología y universales, diversidad lingüística y reconstrucción genealógica.

9. A partir de esta propuesta, el Atlas UNESCO de las lenguas en peligro en el mundo establece que en Costa Rica se hallan nueve lenguas amenazadas. Este cálculo, empero, adolece de algunos errores, posiblemente atribuibles a la información consultada. Los errores en la consideración del estado de algunas de estas lenguas se debe, posiblemente, a las inexactitudes de las fuentes y a algunos datos extraños del Censo Nacional de Población del 2000. En primer lugar, el térraba (variedad costarricense del teribe o naso) debería considerarse extinto, pues no quedan hablantes fluidos ni semifluidos. Por su parte, según el Atlas, la lengua chorotega, hablada hasta el siglo XVIII en el norte de Costa Rica, se encuentra en situación crítica, pero en realidad debe catalogarse como extinta sin lugar a dudas, pues no existen hablantes de ningún tipo. En segundo lugar, el guaymí y el ngäbere se tratan como lenguas distintas, debido posiblemente a un problema en la denominación. El Censo habla de guaymíes como término global que incluye a los ngäbe y a los "sabaneros" (los buglere), dos grupos distintos con sus propias lenguas que cohabitan en los mismos territorios tanto en Panamá como en Costa Rica. El Atlas toma los datos del Censo en su totalidad (incluyendo ngäbes y buglere) al referirse a los guaymíes, mientras que se basa en un "recent article by Constenla" (no se especifica ninguna referencia bibliográfica) para consignar la cifra de 2174 hablantes del ngäbere, del que señala que otro nombre alternativo es guaymí. Con esto, surge una confusión achacable a la variedad de glotónimos con los que muchas veces se denomina la misma lengua. No entraremos en más detalle sobre algunos otros errores. Centrándonos únicamente en los idiomas de los que nos ocupamos en este artículo y haciendo caso omiso de los errores, la situación global de las lenguas minoritarias de Costa Rica se describe en el Atlas del siguiente modo: el boruca y el térraba están en situación crítica; el bribri, el cabécar y el guaymí se encuentran en situación vulnerable; el criollo limonense está en peligro; y el malecu se cataloga como seriamente en peligro. No obstante, la situación global se señala como vulnerable para el ngäbe y el teribe (variedad geolectal de térraba hablada en Panamá), ya que estas dos lenguas cuentan con hablantes en Panamá.

10. En el caso del criollo limonense, el problema de la ortografía reviste características especiales si se toma en cuenta el dilema de su representación o no con una escritura desviante del inglés norteamericano o británico (véase al respecto Portilla 1996). Asimismo, es particularmente problemática la decisión acerca de si debe crearse un sistema de escritura "práctico" (con fines didácticos y no de investigación) para la lengua de señas (véase Sánchez Avendaño 2005). En ambos casos, entonces, posiblemente habría que asignar un puntaje de 0 .

11. La documentación también incluye, según Himmelmann (2006), lo que se denomina "conocimiento metalingüístico" o habilidad de los hablantes de proporcionar sistematizaciones e interpretaciones de los eventos y elementos lingüísticos.

12. Véase la página web del Departamento de Investigación del CENAREC de Costa Rica (www. cenarec.org). 
13. En el anexo a este artículo se consignan con detalle las publicaciones relativas a la descripción y documentación de todos los idiomas a los que nos hemos referido en los párrafos anteriores.

14. Una excepción a esto serían los dos métodos publicados para la enseñanza-aprendizaje del bribri (Constenla et al 1998, Jara y García 2009), los cuales incluyen expresiones de uso común en la conversación cotidiana.

15. Existen, además, muchas colecciones de textos de la tradición oral de los respectivos pueblos en todas estas lenguas y en cabécar, pero sin anotación, lo cual les resta utilidad a tales corpus, pues no pueden ser comprendidos ni trabajados por quienes no sean hablantes competentes de los idiomas.

\section{Bibliografía}

Abarca González, Rocío. 1985. “Análisis fonológico del guaymí movere". En: Estudios de Lingüística Chibcha IV: 7-46.

. 1988. "Uso y frecuencia de los sufijos del núcleo predicativo en las narraciones tradicionales borucas". En: Estudios de Lingüistica Chibcha 7: 75-120.

Alvarado Chaves, Magda. 1989. "Los actantes en la narración tradicional boruca". En: Revista de Filología y Lingüística XV (2): 103-118.

Álvarez Navarro, Emilia et al. 1979. Análisis fonológicos y gramática generativotransformacional del maleku (guatuso). Trabajo final de graduación. Universidad de Costa Rica.

Amador Brenes, Jenny. 1986. La pluralización en el bribri de Coroma. Tesis de licenciatura. Universidad de Costa Rica.

Anglin Edwards, Joice. 2002. Anancy en Limón. Cuentos afro-costarricenses. San José: Editorial de la Universidad de Costa Rica.
Arel, Dominique. 2002. "Language categories in censuses: backward- or forward-looking?". En: Kertzer y Arel (eds.): 92-120.

Arosemena B. y Melquíades A. 1975. " $L a$ lingüística de texto aplicada a un texto narrativo guaymi". En: Estudios sobre el discurso en guaymí: 1-34.

1983. "Principales rasgos fonológicos del guaymí". En: Revista Latinoamericana de Estudios Etnolingüísticos 3: 87-119.

Arosemena, Frances. 1975. "Los participantes en un texto narrativo guaymí". En: Estudios sobre el discurso en guaymí: 61-82.

Barrantes, Ramiro, María Eugenia Bozzoli y Patricia Gudiño (eds.). 1986. Memoria del Primer Simposio Científico sobre Pueblos Indígenas de Costa Rica. San José: MOPT e Instituto Geográfico de Costa Rica.

Bauman, James. 1980. A Guide to Issues in Indian Language Retention. Washington: Center for Applied Linguistics.

Bertoglia Richards, Mafalda. 1983. "Los clasificadores numerales en los dialectos cabécares de Ujarrás y Chirripó". En: Estudios de Lingüística Chibcha II: 3-13.

Betancourt de Sánchez, Helia y Adolfo Constenla Umaña. 1981. "La expedición al territorio de los guatusos: una crónica colonial hispana y su contraparte en la tradición oral indígena”. En: Revista de Filología y Lingüística 7 (1-2): 19-34.

Bett Melles, Gavin. 1990. La gramática de casos: el modelo y su aplicación al bribri. Tesis de maestría. Universidad de Costa Rica.

1991. "Un modelo para el análisis de un texto narrativo bribri". En: Preuss (ed.): 15-20. 
Bourland Hawley, David. 1975. "Un análisis fonológico del cabécar". En: Revista de Filología y Lingüística I (2): 49-68.

1976. "Una gramática generativatransformacional del cabécar". En: Revista de Filología y Lingüistica II (3): 49-112.

Bozzoli de Wille, María Eugenia. 1972. "Notas sobre el parentesco entre los indios talamanqueños y guatusos de Costa Rica". En: América Indígena XXXII(2): 553-571.

1977a. "Narraciones bribris". En: Vinculos 2(2):165-200.

. 1977b. "Narraciones bribris". En: Vínculos 3(1-2):67-104.

. 1986. El indígena costarricense y su ambiente natural: Usos y adaptaciones. San José: Editorial Porvenir.

Britton, Carol. 2008. Cuentos afrocaribeños de la araña Anancy y sus amigos. San José: Instituto Costarricense de Enseñanza Radiofónica.

Calvo Shadid, Annette. 1994. "Funciones discursivas del aspecto en bribri". En: Estudios de Lingüistica Chibcha XIII: 101-117.

Camacho Nassar, Carlos. 1996. En la frontera del siglo XX. La exclusión de los guaymíes en Costa Rica. San José: Oficina de Publicaciones de la Universidad de Costa Rica.

Castro, Damaris. 2008. "Brúnkahk Tek: An Extinct Language. En: Letras 43:51-74.

Cervantes Gamboa, Laura. 1991. "Los géneros musicales bribris: aspectos sociolingüísticos de su ejecución". En: Káñina XV(1-2): 243-254.
. 1993. "Análisis componencial de la terminología de parentesco bribri". En: Estudios de Lingüistica Chibcha XII: $35-52$.

Constenla Umaña, Adolfo. 1975. La lengua guatusa: fonología, gramática y léxico. Tesis de licenciatura. Universidad de Costa Rica.

. 1977. "La terminología de parentesco de los indios boruca". En: Revista de Filología y Lingüistica III (5): 31-38.

. 1982a. "Algunos aspectos de la etnografía del habla de los indios guatusos". En: Estudios de Lingüística Chibcha I: 5-31.

. 1982b. "Sobre la construcción ergativa en la lengua guatusa". En: Revista de Filología y Lingüistica VIII (1-2): 97-101.

1982c. "La nasalidad en relación con el tono y la intensidad en bribri". En: Revista de Filología y Lingüistica VIII (1-2): 109-112.

1983. "Descripción del sistema fonemático del guatuso". En: Revista de Filología y Lingüística IX (1): 3-19.

. 1985. "La voz antipasiva en guatuso". En: Estudios de Lingüistica Chibcha V: 85-95.

. 1986a. "La función de una alternancia gramatical guatusa en el discurso narrativo tradicional". En: Barrantes, Bozzoli y Gudiño (comp.): 119-127.

1986b. "Textos bilingües de cuatro narraciones tradicionales borucas". En: Revista de Filología y Lingüística XII (1): 79-101.

.1986c. Abecedario ilustrado térraba. San José: Ministerio de Educación Pública. 
. 1988. "El guatuso de Palenque Margarita: su proceso de declinación". En: Estudios de Lingüística Chibcha 7: 7-37.

- 1990a. "Morfofonología y morfología derivativa guatusas". En: Estudios de Lingüistica Chibcha 9: 81-122.

. 1990b. "The Language of the Bribri Ritual Songs". En: Latin American Indian Literatures Journal 6 (1): 14-35.

. 1991. "Tres textos guatusos del ciclo narrativo de las uniones con los animales". En: Estudios de Lingüistica Chibcha 10:101-119.

. 1992a. Abecedario ilustrado bribri. San José: Comisión Costarricense de Cooperación con la UNESCO.

. 1992b. "Hagiografía y antihagiografía en la tradición oral guatusa". En: Revista de Filología y Lingüística XVIII (1): 83-124.

. 1995. "Onomástica guatusa". En: Estudios de Lingüistica Chibcha XIV: 41-88.

- 1996. Poesía tradicional indígena costarricense. San José: Editorial de la Universidad de Costa Rica.

. 1997-98. "Las flexiones de persona gramatical y el sistema de casos en naso (teribe-térraba)". En: Estudios de Lingüistica Chibcha XVI-XVII: 247257.

. 1998. Gramática de la lengua guatusa. Heredia: Editorial de la Universidad Nacional.

. 1999. "El respeto a la vida animal en la tradición oral guatusa". En: Revista de Filología y Lingüística XXV (2):119-133.
. 2003. "Dos textos guatusos sobre los profetas del cataclismo". En: Estudios de Lingüistica Chibcha XXII: 61-128.

. 2006. Poesía bribri de lo cotidiano. San José: Editorial de la Universidad de Costa Rica.

. 2007a. La lengua de Térraba. San José: Editorial de la Universidad de Costa Rica.

. 2007b. "Traducción y análisis de narraciones guatusas sobre ogros". Informe final de proyecto de investigación (sin publicar).

. 2011a. Leyendas y tradiciones borucas. Tomo II. San José: Editorial de la Universidad de Costa Rica

. 2011b. Porétecá maráma. Cantos guatusos de entretenimiento. Informe final de proyecto de investigación (sin publicar).

Constenla Umaña, Adolfo y Espíritu Santo Maroto. 1979. Leyendas y tradiciones borucas. San José: Editorial de la Universidad de Costa Rica.

2011. Leyendas y tradiciones borucas. Tomo I. San José: Editorial de la Universidad de Costa Rica.

Constenla Umaña, Adolfo y Enrique Margergy Peña. 1978. Bribri I. San José: Departamento de Publicaciones de la Universidad de Costa Rica.

Constenla Umaña, Adolfo y Enrique Margergy Peña. 1979. Bribri II. San José: Departamento de Publicaciones de la Universidad de Costa Rica.

Constenla Umaña, Adolfo, Eustaquio Castro y Antonio Blanco. 1993. Laca Majifijica. La transformación de la tierra. San José: Editorial de la Universidad de Costa Rica. 
Constenla Umaña, Adolfo y Eustaquio Castro C. 1994. Ata malécu jaicaco irijionh. Escribamos en idioma guatuso. Cartago: Litografía e Imprenta Alvarado y Asociados.

. 2011. Pláticas sobre felinos. San José: Editorial de la Universidad de Costa Rica.

Constenla Umaña, Adolfo y Feliciano Elizondo Figueroa. 1994. "Observaciones preliminares sobre el habla infantilizada en bribri”. En: Estudios de Lingüística Chibcha 13: 119-127.

Constenla Umaña, Adolfo y Leonicio Bejarano. 1994. Alfabeto práctico ilustrado guaimí. San José: Ministerio de Educación Pública.

Constenla Umaña, Adolfo, Feliciano Elizondo Figueroa y Francisco Pereira Mora. 1998. Curso básico de bribri. San José: Editorial de la Universidad de Costa Rica.

COOPA. 1996. Narraciones bribris. Así cuentan los mayores... San José: Fundación Coordinadora de Pastoral Aborigen.

. 1997. Narraciones Ngäbes: revitalización de la cultura tradicional. San José: Fundación Coordinadora de Pastoral Aborigen.

Córdoba, Patricia. 2001-2002. "Dos relatos bocotás (Dialecto de Chiriquí)". En: Estudios de Lingüistica Chibcha XX-XXI: 29-46.

Cruz Volio, Gabriela. 2010. "El sistema de transitividad en las cláusulas materiales del bribri según la gramática sistémicofuncional". En: Revista de Filología y Lingüistica XXXVI (2): 133-154.

.2011. "La cláusula como mensaje en bribri según la gramática sistémico-funcional de Halliday”. En: Káñina XXXV(1): 97-114.
Díaz Virgin, Beulah et al. 1976. Una gramática generativa transformacional de un idiolecto del Brorán (Térraba). Trabajo final de graduación. Universidad de Costa Rica.

Dickeman-Datz, Margaret. 1984. "Split ergativity and Subject in Bribri". En: Estudios de Lingüística Chibcha 3: 113-134.

. 1985a. "Transitivity in Indefinite Voice in Bribri”. En: International Journal of American Linguistics 51(4): 388-390.

. 1985b. "Eliminación de la ambigüedad pronominal en el discurso del criollo limonense". En: Revista de Filología y Lingüística XI (1): 119-130.

Edwards Mundall, Gilbert. 2006. "Etnoentomología cabécar". En: Estudios de Lingüistica Chibcha XXV: 7-63.

Estudios sobre el discurso en guaymí. Lenguas de Panamá 8. 1975. Panamá: Instituto Lingüístico de Verano.

Fasold, Ralph. 1996. La Sociolingüistica de la Sociedad. Introducción a la Sociolingüistica. Madrid: Visor Libros.

Fernández Torres, Severiano, Marine HedströmRojas y Freddy Obando Martínez. 2005a. Sa ñąyuwä. Sa siwạwa. Estudiemos cabécar 3. San José: Fundación Nairi.

Fernández Torres, Severiano, Marine HedströmRojas y Freddy Obando Martínez. 2005b. Sa ñayuwä. sa siwawa. Estudiemos cabécar 4. San José: Fundación Nairi.

Fernández Torres, Severiano y Marine Hedström-Rojas. 2011a. Sa ñayuwä. sa siwawa. Estudiemos cabécar 5. San José: Fundación Nairi. 
Fernández Torres, Severiano y Marine Hedström-Rojas. 2011b. Sa ñayuwä. sa siwawa. Estudiemos cabécar 6. San José: Fundación Nairi.

Fernández Torres, Severiano y Marine Hedström-Rojas. 2011c. Siböte i-ka dieyá. El banquete de Sibö. San José: Fundación Nairi.

Flores Solórzano, Sofía. 2009. "Los mamíferos en la clasificación etnobiológica de la comunidad de Amubre". En: Estudios de Lingüistica Chibcha XXVIII: 7-46.

García Segura, Guillermo. 1986. Stsawö we. Texto para la enseñanza de la lectura y escritura en la lengua bribri. San José: Asesoría Nacional de Educación Indígena.

Giles, H. (ed.). 1977. Language, Ethnicity and Intergroup Relations. Londres: Academic Press.

Giles, Howard, R. Y. Bourhis y D. M. Taylor. 1977. "Towards a theory of language in ethnic group relations”. En: Giles, H. (ed.): 307-348.

Gippert, Jost, Nikolaus P. Himmelmann y Ulrike Mosel. 2006. Essentials of Language Documentation. Berlín: Mouton de Gruyter.

Gudiño Fernández, Patricia. 1994. Yëjkuöalâttsitsi a. San José: Comisión Costarricense de Cooperación con la UNESCO.

Hagège, Claude. 2002. No a la muerte de las lenguas. Barcelona: Paidós.

Hedström-Rojas, Marine y Ovidio Martínez Sanabria. 2005a. Sa ñayuwä. sa siwáwa. Estudiemos cabécar 1. San José: Fundación Nairi.
Hedström-Rojas, Marine y Ovidio Martínez Sanabria. 2005b. Sa ñayuwä. sa siwawa. Estudiemos cabécar 2. San José: Fundación Nairi.

Hernández Poveda, Dora. 1992. “Análisis componencial del sistema de parentesco del dialecto sur del cabécar". En: Estudios de Lingüística Chibcha 11:13-33.

Herranz, Atanasio, Marvin Barahona y Ramón Rivas (eds.). 1995. Educación Bilingüe e Intercultural en Centroamérica y México. Tegucigalpa: Editorial Guaymuras.

Herzfeld, Anita. 1994. "Language and identity: the black minority in Costa Rica". En: Revista de Filología y Lingüística XX (1): 113-142.

. 2002. Mekaytelyuw: La lengua criolla. San José: Editorial de la Universidad de Costa Rica.

. 2008. "Los criollos en Centroamérica". En: Palacios (coord.): 77-94.

.2011. "Una evaluación de la vitalidad lingüística del inglés criollo de Limón: su vigencia o su desplazamiento". Revista de Filología y Lingüistica 37 (2) pp: 107-131.

Himmelmann, Nikolaus P. 2006. "Language documentation: What is it and what is it good for?". En: Gippert, Himmelmann y Mosel (eds.): 1-30.

Instituto de Estudios de las Tradiciones Sagradas de Abia Yala. 2000. Narraciones Malekus. San José: Fundación Coordinadora de Pastoral Aborigen.

Jara Murillo, Carla. 1986. Abecedario ilustrado boruca. San José: Ministerio de Educación Pública. 
. 1987. "El campo léxico de la vivienda en el bribri de Coroma". En: Estudios de Lingüistica Chibcha VI: 109-187.

. 1989. "Categorías en el sistema verbal del bocotá de Chiriquí". En: Estudios de Lingüística Chibcha VIII: 101-139.

.1991. "Estructura causal de una narración bribri”. En: Preuss (ed.): 11-14.

. 1993. I ttè. Historias bribris. San José: Editorial de la Universidad de Costa Rica.

. 1995a. "Caracterización del sistema verbal bribri a partir del discurso narrativo de Coroma". En: Estudios de Lingüística Chibcha XIV: 7-29.

1995b. "Transitividad en el discurso bribri". En: Revista de Filología y Lingüistica XXI (2): 93-105.

. 1995c. Text and context of the suwwo. Bribri oral tradition. Tesis doctoral. Louisiana State University.

. 1997-98. "El acto de habla de "desear" en la narrativa tradicional bribri". En: Estudios de Lingüistica Chibcha XVIXVII: 105-112.

. 1998. "Estructura de la conversación y diálogo de géneros en la lengua bribri (chibcha)". Memoria del IV Encuentro de Lingüistica en el Noroeste. México: Universidad de Sonora.

. 2002. "Tipología del orden de palabras en bribri". En: Revista de Filología y Lingüistica XXVIII (2): 111-138.

. 2003. "Codificación de participantes en una narración bribri". En: Estudios de Lingüistica Chibcha XXII: 33-60.
. 2004a. "Observaciones para el estudio dialectológico de la lengua bribri". En: Estudios de Lingüística Chibcha 23: 89-120.

. 2004b. "Hispanismos en la conversación bribri (fam. chibcha)". En: Sánchez (ed.): 575-586.

. 2006. "Estructura y textura en un texto tradicional bribri". En: Revista de Filología y Lingüística XXXII (1): 157209.

Jara Murillo, Carla y Alí García Segura. 2008. Cargos tradicionales del pueblo bribri: Sĩót tãmĩ - Óköm - Awá. San José: Instituto Costarricense de Electricidad.

.2009. Se' é' yawö bribri wa. Aprendemos la lengua bribri. San José: EDITORAMA.

Javilla, Luciano et al. s.f. Kukwe kira ketarike ngäbere. Cinco cuentos guaymíes. Panamá: Panacopias.

Jiménez, Floria. 1987. Descripción componencial del mundo mitológico bribri. Tesis de licenciatura. Universidad de Costa Rica.

Kertzer, David I. y Dominique Arel (eds.). 2002. Census and Identity. The Politics of Race, Ethnicity, and Language in National Censuses. Cambridge: Cambridge University Press.

Kopesec, Michael. 1975. "Los elementos verbales y sustantivos y la oración en guaymí”. En: Levinsohn (ed.): 19-82.

Krohn, Haakon. 2012. El mantenimiento de la referencia discursiva en la narrativa tradicional malecu. Tesis de maestría. Universidad de Costa Rica.

Lamounier, Alice. 2009. "La enseñanza del cosmos: la experiencia de los maestros de 
cultura bribris y cabécares". En: Inter-c- $a$ mbio 6(7): 31-54.

Levinsohn, Stephen (ed.). 1975. Observaciones preliminares sobre los sistemas gramaticales de las lenguas chibchas. Lenguas de Panamá 2. Panamá: Instituto Nacional de Cultura.

Lininger Ross, Barbara. 1977. "La frase nominal del dialecto brorán del Térraba". En: Revista de Filología y Lingüística III (6):85-92.

- 1981. "Estudios sobre el guaymí ngäbere: fonología, alfabeto y diccionario provisional". En: Revista de Filología y Lingüistica VII (1-2): 101-115.

. 1982. "El alfabeto práctico ngäbere y las listas ilustrativas". En: Revista de Filología y Lingüistica VIII (1-2): 137-154.

1990. "Cómo proponer matrimonio en bribri”. En: Estudios de Lingüistica Chibcha 9-10: 65-80.

Lininger Ross, Barbara et al. 1978. "Un análisis fonológico de un idiolecto del brorán (térraba)". En: Revista de Filología y Lingüistica IV (1): 55-74.

López Grazioso, Diana. s.f. Comuniquémonos mejor. San José: s.e.

Madrigal González, David. 1984. Análisis sintáctico de la preoración movere (guaymí): oraciones negativas, interrogativas e imperativas o exhortativas. Tesis de maestría. Universidad de Costa Rica.

Margery Peña, Enrique. 1982a. Diccionario fraseológico bribri-español/españolbribri. San José: Editorial de la Universidad de Costa Rica. 1982b. "Descripción del sistema fonológico de un idiolecto del cabécar de Ujarrás". En: Estudios de Lingüística Chibcha I: 33-44.

. 1983. "Sobre el adjetivo cabécar". En: Estudios de Lingüística Chibcha II: 67-80.

. 1984. "Etnoornitología del cabécar de Ujarrás". En: Estudios de Lingüistica Chibcha III: 7-63.

. 1985a. "Morfología flexiva del verbo cabécar". En: Estudios de Lingüística Chibcha IV: 101-154.

. 1985b. "Alfabeto práctico pandialectal de la lengua cabécar". En: Revista de Filología y Lingüistica XI (1): 131-137.

. 1985c. "Morfemas derivativos en la cualificación nominal cabécar". En: Revista de Filología y Lingüística XI (2): 99-110.

. 1986a. "Cuatro leyendas cabécares". En: Estudios de Lingüistica Chibcha V: 45-57.

. 1986b. "Etnoespantología cabécar". En: Revista de Filología y Lingüistica XII (1): 153-188.

.1986c. Abecedario ilustrado cabécar. San José: Ministerio de Educación Pública.

1986d. "Apuntes sobre la gramática cabécar". En: El Ateneo de Costa Rica 2: 101-154.

. 1988. "La nasalización en el bocotá de Chiriquí". En: Estudios de Lingüistica Chibcha VII: 65-73.

. 1989a. Diccionario cabécar-español/ español-cabécar. San José: Editorial de la Universidad de Costa Rica. 
. 1989b. "El origen del mundo en una narración bocotá". En: Estudios de Lingüística Chibcha VIII: 153-182.

. 1989c. "Cuatro relatos mitológicos bocotás de los yé nansére ('seres malos')". En: Revista de Filología y Lingüística XV (2): 51-74.

. 1990a. "The Tar-Baby Motif in a Bocota Tale: Blísigi Sigabá Gule ("The Opossum and the Agouti"). En: Latin American Indian Literatures Journal 6 (1): 1-13.

1990b. "La leyenda de la madre del Sol y de la Luna en una versión guaymí y en una versión el bocotá de Chiriquí". En: Selected Papers from the VII International Symposium on Latin American Indian Literatures: 23-42.

. 1990c. "La leyenda del origen de Jirondái en una versión bocotá de Chiriquí: texto y comentarios". En: Revista de Filología y Lingüistica XVI (1): 97-110.

. 1990d. "Doble Kuabága: el ciclo épico bocotá de Las Cuatro Guerras". En: Estudios de Lingüistica Chibcha IX: 123172.

- 1992. "Apuntes sobre tres versiones bocotás de la leyenda de "la madre del maíz"”. En: Revista de Filología y Lingüistica XVIII (1): 75-81.

. 1993a. "Textos y comentarios de cuatro relatos bocotás referentes a cataclismos". En: Revista de Filología y Lingüística XIX (1): 89-111.

. 1993b. "Dos textos y algunos comentarios en relación con el rol de "trickster" de la guatusa (Dasyprocta punctata) en la narrativa oral de los bocotás de Chiriquí". En: Revista de Filología y Lingüística XIX (2): 71-79.
. 1993c. "Estados de conservación de las lenguas indígenas de Costa Rica frente al español”. En: Sánchez (ed.): 257-266.

1993d. "Vocabulario bocotá". En: Estudios de Lingüistica Chibcha XII: 53-93.

. 1995. "Sibö (relato mitológico cabécar"). En: Estudios de Lingüística Chibcha XIV: 31-39.

.1996. "Fonología del bocotá de Chiriquí". En: Estudios de Lingüística Chibcha 15: 7-26.

1997. "De hombres y animales. Dos relatos de la tradición oral de los bocotá de Chiriquí". En: Revista de Filología y Lingüística XXIII (2):175-183.

. 1999. "Seis mitos de origen correspondientes a la tradición oral de los bocotás de Chiriquí". En: Revista de Filología y Lingüística XXV (2): 135-142.

Margery Peña, Enrique y Francisco Rodríguez Atencio. 1992. Narraciones bocotás (dialecto de Chiriquí). San José: Editorial de la Universidad de Costa Rica.

Maroto, Espíritu Santo. 1999. Lengua o dialecto boruca o brúnkajk (recopilación y presentación de Miguel Quesada Pacheco). San José: Editorial de la Universidad de Costa Rica.

Masís Morales, Óscar y Elizabeth Mora Lobo. 1985. "Las oraciones completivas en el criollo de Limón: análisis sintáctico de un idiolecto". En: Revista de Filología y Lingüística XI (2): 111-121.

Mejía Marín, Noemy et al. 1995. Historias malecus. Heredia: EUNA.

Monge Bermúdez, Lilliam. 1988. Morfología derivativa de los verbos intransitivos del 
bribri. Tesis de licenciatura. Universidad de Costa Rica.

Montezuma Montezuma, Javier. 1995. Ari blide ngabere (Aprendamos Ngäbe). Alajuela: Alfa-editora.

Murillo Miranda, José. 2008. "Notas sobre la lengua guaymí en Costa Rica". En: Letras 43: 75-90.

Murillo, José y Juan Quesada. 2008. "Relaciones estructurales de un texto ngäbére". En: Estudios de Lingüistica Chibcha XXVII: 101-116.

Nonaka, Angela. 2004. "The forgotten endangered languages: Lessons on the importance of remembering from Thailand's Ban Khor Sign Language”. En: Language in Society 33: 737-767.

Ovares, Sandra y Carmen Rojas. 2008. "La enseñanza de las lenguas indígenas en Costa Rica". En: Letras 43: 11-21.

Pacchiarotti, Sara. 2010. "La estructura de modo y el sistema de MODO en la cláusula del bribri de Coroma según la gramática sistémico-funcional". En: Revista de Filología y Lingüística XXV (2): 233-249.

Palacios Alcaine, Azucena (coord.). 2008. El español en América. Contactos lingüisticos en Hispanoamérica. Barcelona: Ariel.

Palmisano, Antonio (ed.). 2008. Identità delle comunità indigene del Centro America. Roma: IILA.

Payne, Thomas. 1982. "Subject in Guaymí”. En: Estudios de Lingüistica Chibcha I: 45-76.

Pizarro Chacón, Ginneth. 2005. "Etnoornitología guatusa". En: Letras 37: 139-165.
Portilla Chaves, Mario. 1986. "Un caso de muerte de lenguas: el térraba". En: Estudios de Lingüistica Chibcha 5: 97- 246.

1993. "Fonemas segmentales en el criollo inglés de Limón”. En: Revista de Filología y Lingüística XIX (2): 89-97.

. 1995. "Tono en el criollo inglés de Costa Rica". En: Revista de Filología y Lingüística XXI (1): 135-139.

. 1996. "Una ortografía para el criollo inglés de Costa Rica. En: Revista de Filología y Lingüística XXII (2): 87-103.

1997. "Tiempo-aspecto-modo en el criollo inglés de Costa Rica". En: Revista de Filología y Lingüística XXIII (2): 161-172.

. 1999-2000. "El sistema numeral del térraba". En: Estudios de Lingüistica Chibcha XVIII-XIX: 53-72.

. 2004. "Oraciones causativas en el inglés criollo de Costa Rica". En: Revista de Filología y Lingüística XXX (1): 163-179.

. 2005. "Cláusulas relativas en el inglés criollo de Costa Rica". En: Revista de Filología y Lingüística XXXI (1):251-266.

. 2010. "Análisis acústico de la longitud vocálica en el inglés criollo de Limón". En: Revista de Filología y Lingüística XXXVI (2): 175-192.

Preuss, Mary (ed.). 1991. Past, present and future. Selected Papers on Latin American Indian Literatures. Culver City: Labyrinthos.

Proyecto Río Frío et al. 2011a. Diccionario malecu. San José: s.e.

Proyecto Río Frío et al. 2011b. Malecu usirraca. Libro de leyendas Malecu. San José: s.e. 
Proyecto Río Frío et al. 2011c. Silabario Malecu jaica. San José: s.e.

Quesada, Juan Diego. 1996. "Enfoque y topicalidad en boruca: el caso de añ". En: Estudios de Lingüística Chibcha 15: 43-58.

. 2000a. "Synopsis of a Boruca terminal speaker”. En: Amerindia 25: 65-86.

. 2000b. "The grammaticalization of specificity (and beyond) in Boruca". En: International Journal of American Linguistics 66 (3): 549-562.

. 2001-2002. "Adiós boruca: Sibú ki ba wí?ra moréng...". En: Estudios de Lingüistica Chibcha 20-21: 55-64.

. 2006. "Sobre las relaciones gramaticales del buglere". En: Estudios de Lingüística Chibcha XXV: 65-78.

. 2007. "Lo que no es en buglere". En: Estudios de Lingüistica Chibcha XXVI: 131-146.

.2008a. "El buglere: lengua obsolescente". En: Letras 43: 39-50.

. 2008b. "Las lenguas chibchas y sus hablantes: resistencia, obsolescencia e indiferencia”. En: Palmisano (ed.), 183-194.

Quesada, Juan Diego y Miguel Quesada Pacheco. 1995. "Boruca ki: de definido a específico y la hipótesis de las funciones contiguas". En: Estudios de Lingüística Chibcha XIV: 89-99.

Quesada Pacheco, Miguel Ángel. 1995a. "Revitalización de las lenguas indígenas de Costa Rica: el caso del boruca". En: Herranz et al (eds.): 101-128. 1995b. Hablemos boruca (Chá dï di tégat tegrá). San José: Ministerio de Educación Pública.

.1996. Shán̈ rójc brún̈cajc rójc. Narraciones borucas. San José: Editorial de la Universidad de Costa Rica.

.1997a. Historias de los Antiguos de Boruca. Div xasúj rójc ígui téc rójc. Quito: Ediciones Abya-Yala.

. 1997b. "Réquiem por una lengua indígena costarricense: el caso del boruca". En: América Indígena 57 (3-4): 295-313.

. 1997-98. "El adjetivo boruca". En: Estudios de Lingüistica Chibcha XVIXVII: $157-165$.

. 1999-2000. "Situación actual y futuro de las lenguas indígenas de Costa Rica". En: Estudios de Lingüistica Chibcha 18-19: 7-34.

. 2006. "Cinco relatos guaymíes". En: Estudios de Lingüistica Chibcha XXV: 79-92.

. 2008a. "América Central". En: Palacios (coord.): 57-75.

. 2008b. Gramática de la lengua guaymí (ngäbe). Múnich: Lincom.

2008c. "Las lenguas ístmicas: entre obsolescencia y resistencia". En: Letras 43: 23-37.

. 2009. "El panteón lingüístico chibcha y sus vecinos". En: Letras 45: 11-24.

Quesada Pacheco, Miguel y Carmen Rojas Chaves. 1999. Diccionario borucaespañol/español-boruca. San José: Editorial de la Universidad de Costa Rica. 
Quesada Pacheco, Miguel Ángel y Bertilo Vejerano Palacio. 2010. Kugwe ngäbere. Leyendas y tradiciones ngäbes. San José: Editorial de la Universidad de Costa Rica.

Retana Castro, Priscilla. 1993. Descripción del aspecto verbal en la lengua costarricense de señas. Tesis de maestría. Universidad de Costa Rica.

Rimolo, Annamaria. 2007. "Aplicación de los postulados de la teoría clasificatoria etnobiológica de Brent Berlin (1992) al universo ornitológico del bribri de Coroma". En: Estudios de Lingüística Chibcha XXVI: 7-100.

Rojas, Álvaro. 1990. Análisis del discurso de la narrativa boruca. Tesis de maestría. Universidad de Costa Rica.

Rojas Chaves, Carmen. 1988. "Descripción y análisis de la fiesta de los diablitos de Boruca". En: Estudios de Lingüística Chibcha VII: 121-135.

. 1992. "Morfología derivativa de la lengua boruca". En: Estudios de Lingüística Chibcha XI: 35-64.

. 1997-1998. "Revitalización lingüística de las lenguas indígenas de Costa Rica". En: Estudios de Lingüística Chibcha 16:9-17.

. 2002. "La enseñanza de las lenguas indígenas en Costa Rica". En: Educare 3: $177-186$.

. 2005. "La vieja Shecra, encanto del río. Texto boruca". En: Estudios de Lingüistica Chibcha XXIV: 123-131.

. 2006. "Actitudes hacia la enseñanza de las lenguas indígenas". En: Letras 39: 267-271.
Sánchez, Juanita y Gloria Mayorga. 1994. Se síwa Nuestras tradiciones. Costumbres y tradiciones bribris. San José: Comisión Costarricense de Cooperación con la UNESCO.

Sánchez Avendaño, Carlos. 2005. "El español y el LESCO en el marco de la enseñanza de una segunda lengua para las personas sordas en Costa Rica". En: Revista Educación 29(2): 217-232.

.2009a. "Situación sociolingüística de las lenguas minoritarias de Costa Rica y censos nacionales de población 1927-2000: Vitalidad, desplazamiento y autoafiliación etnolingüística”. En: Revista de Filología y Lingüística 35 (2): 233-273.

. 2009b. "La voz media en bribri y la hipótesis de la elaboración relativa de los eventos". En: Estudios de Lingüística Chibcha XXVIII: 47-73.

. 2011. El desplazamiento de la lengua guatusa en contacto con el español: Identidad étnica, ideologías lingüísticas y perspectivas de conservación. Tesis doctoral. Universidad Autónoma de Madrid.

. 2012. "El papel de la escuela en el desplazamiento y en la conservación de la lengua malecu". En: Revista Educación 36 (1): 1-34.

Sánchez Corrales, Víctor. 1979. "El maleku: lengua ergativa". En: Revista de Filología y Lingüistica V (1-2): 67-71.

. 1984. "Análisis fonológico del guatuso". En: Estudios de Lingüistica Chibcha 3: 143-178.

. (ed.). 1993. Memoria del IV Congreso Costarricense de Filología, Lingüística 
y Literatura. San José: Oficina de Publicaciones de la Universidad de Costa Rica.

. (ed). 2004. Memoria del XIII Congreso Internacional de la Asociación de Lingüistica y Filología de América Latina (ALFAL). San José: SIEDIN, Universidad de Costa Rica.

Schlabach, Raymond. 1974. "Los fonemas del bribri del Valle de Talamanca". En: América Indígena 34(2): 355-362.

Schlabach, Raymond A. y Stephen H. Levinsohn. 1982. "Some aspects of the bribri verb". En: Estudios de Lingüística Chibcha I: 77-91.

Selected Papers from the VII International Symposium on Latin American Indian Literatures. 1990. California: Labyrinthos.

Simms, E.G. 1990. Un análisis sociolingüístico de las esferas de uso del inglés de Limón en hablantes que residen en San José, Costa Rica, y algunas actitudes de los hablantes y de los descendientes de hablantes de inglés de Limón, que no lo hablan, con respecto a esta lengua. Tesis de licenciatura. Universidad de Costa Rica.

Smith Sharp, Heidi. 1979. "Un análisis fonológico del maleku". En: Revista de Filología y Lingüística V (1-2): 31-54.

Smith, Heidi y Teresita Zamora.1979. "Un análisis tagmémico del dialecto nobere del guaymí”. En: Revista de Filología y Lingüistica V (1-2): 125-137.

Solís Hernández, Mayra. 1989. "Los cuantificadores numerales en el bocotá de Chiriquí". En: Estudios de Lingüistica Chibcha VIII: 141-152.
Spence, Marva. 1997. "A case study of language shift in progress in Port Limon, Costa Rica”. En: Revista de Filología $y$ Lingüistica XXIII (1): 225-234.

. 2001. "Sex, Occupation, Language Choice. The Case of the Limon Creole Speech Community". En: Káñina XXV (1): 49-54.

Umaña Aguiar, Jeanina. 1991. "Cambio de código en Puerto Limón, Costa Rica”. En: Káñina XV (1-2): 199-202.

UNESCO. 2003. Vitalidad y peligro de desaparición de las lenguas. http://www.unesco.org/culture/es/ endangeredlanguages. Consulta: marzo del 2012.

UNESCO. 2009. Atlas UNESCO de las lenguas en peligro en el mundo. http://www.unesco. org/culture/es/endangeredlanguages. Consulta: abril del 2009.

Varas, Valeria y Severiano Fernández. 1989a. Historias cabécares 1. San José: Editorial de la Universidad de Costa Rica.

. 1989b. Historias cabécares 2. San José: Editorial de la Universidad de Costa Rica.

Vásquez Carvajal, Ana Cecilia. 2008. "Caracterización de la situación idiomática de los pueblos indígenas de Costa Rica y su influencia en su educación". En: Revista Educare 12: 61-66.

Villalobos Gamboa, María Eugenia. 1991. "Evidencias de voz antipasiva en bribri". En: Preuss (ed.), 21-25.

1993. "Bribri: lengua con cláusulas relativas del núcleo interno". En: Letras 29-30: 225-239. 
Wilson, Jack. 1970. "Oclusivas sonoras nasalizadas en bribri". En: Revista de la Universidad de Costa Rica 29: 159-163.

. 1974. "Análisis fonológico del bribri". En: América Indígena 34(2): 419-422.

. 1984. "Relative clauses in Bribri". En: Estudios de Lingüistica Chibcha 3: 179-199.

Winkler, Elizabeth Grace. 2000. "Cambio de códigos en el criollo limonense". En: Revista de Filología y Lingüística XXVI (1): 189-196.

Wolfe, Terry. 1970. An exploratory study of the morphology and syntax of the English of the Province of Limon, Costa Rica. Tesis de licenciatura. Universidad de Costa Rica.

Woodward, James. 1991. "Sign Language Varieties in Costa Rica". En: Sign Language Studies 73: 329-346.
. 1992. "Historical Bases of New Costa Rican Sign Language". En: Revista de Filología y Lingüística 18 (1): 127-132.

Wright Murray, Fernando. 1974. Limón Creole: a Syntactic Analysis. Tesis de licenciatura. Universidad de Costa Rica.

1975. "Un análisis sintáctico del habla criolla de Limón”. En: Revista de Filología y Lingüistica I (2): 149-168.

. 1982. "Problemas y métodos para la enseñanza del inglés como segunda lengua a los hablantes del mek-a-tel-yu en la provincia de Limón". En: Revista de Filología y Lingüística VIII (1-2): 129-135.

Zimmer, Tanja. 2011. El español hablado por los afrocostarricenses. Estudio lingüístico y sociolingüístico. Tesis doctoral. Universidad de Colonia. 